\title{
Interplay between Hydrogen and Halogen Bonding in Co-Crystals of Dipyridinylmethyl Oxalamides and Tetrafluorodiiodobenzenes.
}

Baillie A. DeHaven, Anna L. Chen, Emily A. Shimizu, Sahan R. Salpage, Mark D. Smith, and Linda S. Shimizu*

Department of Chemistry and Biochemistry, University of South Carolina, Columbia, South Carolina USA

\section{Table of Contents}

$\begin{array}{ll}\text { Materials and Methods } & \text { S2 }\end{array}$

NMR and mass spec of parent $o$-DPOA co-former $\quad$ S3

NMR and mass spec of parent $m$-DPOA co-former $\quad$ S4

NMR and mass spec of parent $p$-DPOA co-former $\quad$ S5

$\begin{array}{ll}\text { Summary table of crystal growth and habit } & \text { S6 }\end{array}$

Summary table of HB and XB interactions $\quad$ S7-S9

$\begin{array}{lr}\text { Structure, crystal data, and refinement for } o \text {-DPOA } & \text { S10-12 }\end{array}$

Structure, crystal data, and refinement for $(o \text {-DPOA })_{2} \bullet o$-TFDIB $\quad \mathrm{S} 13-\mathrm{S} 14$

Structure, crystal data, and refinement for $o$-DPOA $\bullet m$-TFDIB $\bullet(\text { solv })_{\mathrm{x}} \quad \mathrm{S} 15-\mathrm{S} 17$

Structure, crystal data, and refinement for $(o \text {-DPOA })_{2} \bullet p$-TFDIB $\quad$ S18-S19

Structure, crystal data, and refinement for $o$-DPOA $\bullet(p \text {-TFDIB })_{2} \quad$ S20-S21

Structure, crystal data, and refinement for $m$-DPOA $\bullet \mathrm{H}_{2} \mathrm{O} \quad \mathrm{S} 22-\mathrm{S} 23$

Structure, crystal data, and refinement for $m$-DPOA $\bullet-$ TFDIB $\bullet(\text { solv })_{\mathrm{x}} \quad \mathrm{S} 24-\mathrm{S} 26$

Structure, crystal data, and refinement for $m$-DPOA $\bullet m$-TFDIB $\quad$ S27-S28

Structure, crystal data, and refinement for $m$-DPOA $\bullet m$-TFDIB $\bullet$ DMSO $\quad$ S29-S30

Structure, crystal data, and refinement for $m$-DPOA $\bullet$-TFDIB $\quad$ S31-S32

Structure, crystal data, and refinement for $p$-DPOA $\quad$ S33-S34

Structure, crystal data, and refinement for $p$-DPOA $\bullet$-TFDIB $\quad$ S35-S36

Structure, crystal data, and refinement for $p$-DPOA $\bullet m$-TFDIB $\quad$ S37-S38

Structure, crystal data, and refinement for $p$-DPOA $\bullet(m \text {-TFDIB })_{2} \quad$ S39-S40

Structure, crystal data, and refinement for $p$-DPOA $\bullet$-TFDIB $\quad$ S41-S42

$\begin{array}{ll}\text { FT-IR of } o \text {-DPOA series } & \text { S43 }\end{array}$

FT-IR of $m$-DPOA series $\quad$ S43

FT-IR of $p$-DPOA series $\quad$ S44

$\begin{array}{ll}\text { References } & \text { S44 }\end{array}$ 


\section{Materials and Methods}

Characterization of Compounds: All DPOA ligands were synthesized by the Daniel Reger group and used as received. All TFDIB isomers and solvents were purchased from Oak Ridge Chemical ${ }^{\circledR}$, Thermo Fisher Scientific ${ }^{\circledR}$, VWR ${ }^{\circledR}$, or TCI America ${ }^{\circledR}$ and were used as received without further. ${ }^{1} \mathrm{HNMR}$ spectra were recorded on a Bruker Avance III-HD spectrometer $(300 \mathrm{MHz})$. Chemical shifts are reported as $(\delta \mathrm{ppm})$ with the corresponding integration values. High-resolution mass spectrum data was recorded using a direct exposure probe (DEP) in electron ionization (EI) mode on a Waters QTOF-I quadrupole time-of-flight mass spectrometer. FT-IR data was acquired. FT-IR spectra were obtained using a Perkin Elmer Spectrum 100 FT-IR Spectrometer. Background spectra were recorded from 650 to $4000 \mathrm{~cm}^{-1}$ and taken in 4 scans. The crystalline sample was then added to the sample stage until transmittance was less than $85 \% .32$ scans were then taken from 650 to $4000 \mathrm{~cm}^{-1}$ to obtain spectra.

Crystal Growth. To obtain crystals of the parent ligands, the DPOA ligands (20 mg) were dissolved in a minimal volume of solvent, the solution was filtered, and left to slowly evaporate for 3-5 days until crystals formed. The co-crystals were synthesized by grinding 1:1 stoichiometric ratio of the TFDIB co-formers $(29.6 \mathrm{mg}, 0.07 \mathrm{mmol})$ and DPOA ligands $(20 \mathrm{mg}, 0.07 \mathrm{mmol})$ for approximately 2 min with 3-5 drops of $\mathrm{CHCl}_{3}$. Half of this mixture was added to a vial, and gently heated (when needed) in a minimal amount of solvent until completely dissolved. The samples were then allowed to slowly evaporate for 4-6 days until crystals were formed. The other half of the ground mixture dissolved in DMSO, and water was allowed to vapor diffuse into the solution for approximately 5 days until crystals formed. Both methods were repeated with multiple solvents until co-crystals were obtained.

Crystal Structure Determination: X-ray intensity data was collected at 100(2) K using a Bruker D8 QUEST diffractometer equipped with a PHOTON-100 CMOS area detector and an Incoatec microfocus source (Mo K $\alpha$ radiation, $\lambda=0.71073 \AA$ ). The raw area detector data frames were reduced and corrected for absorption effects using the Bruker APEX3, SAINT+ and SADABS programs. ${ }^{1,2}$ Final unit cell parameters were determined by least-squares refinement of reflections taken from the data set. The structures were solved with SHELXT. ${ }^{3}$ Subsequent difference Fourier calculations and full-matrix least-squares refinement against $F^{2}$ were performed with SHELXL-2016 $6^{3}$ using OLEX2. ${ }^{4}$

Electrostatic Potential Calculations. Electrostatic potentials were calculated using Spartan 10' software package. The crystal structure files (CIFs) of the DPOA compounds were imported and energetically optimized. The energies were then calculated using DFT B3YLP level of theory, using a 6-311++G** basis set under vacuum. Electrostatic potentials for best donor and acceptor were determined using the electrostatic potential map (0.002 e a.u. isovalue) as automatically calculated by the Spartan 10' software. Electrostatic potentials of other donors and acceptors were obtained by manually searching the atom of interest until the value with the largest absolute value was found. 
<smiles>O=C(NCc1ccccn1)C(=O)NCc1ccccn1</smiles>

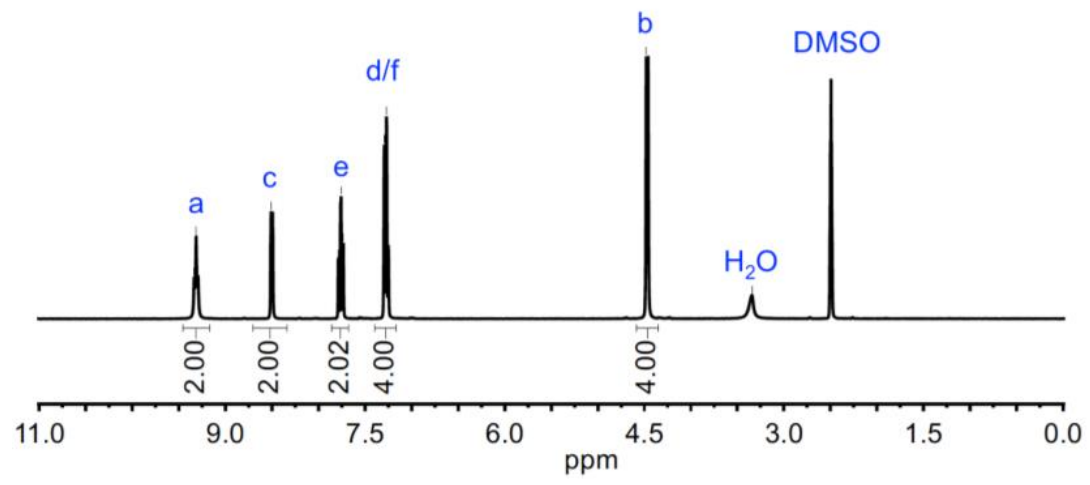

Figure S1. ${ }^{1} \mathrm{H}$ NMR of $o$-DPOA recorded in DMSO-d6.

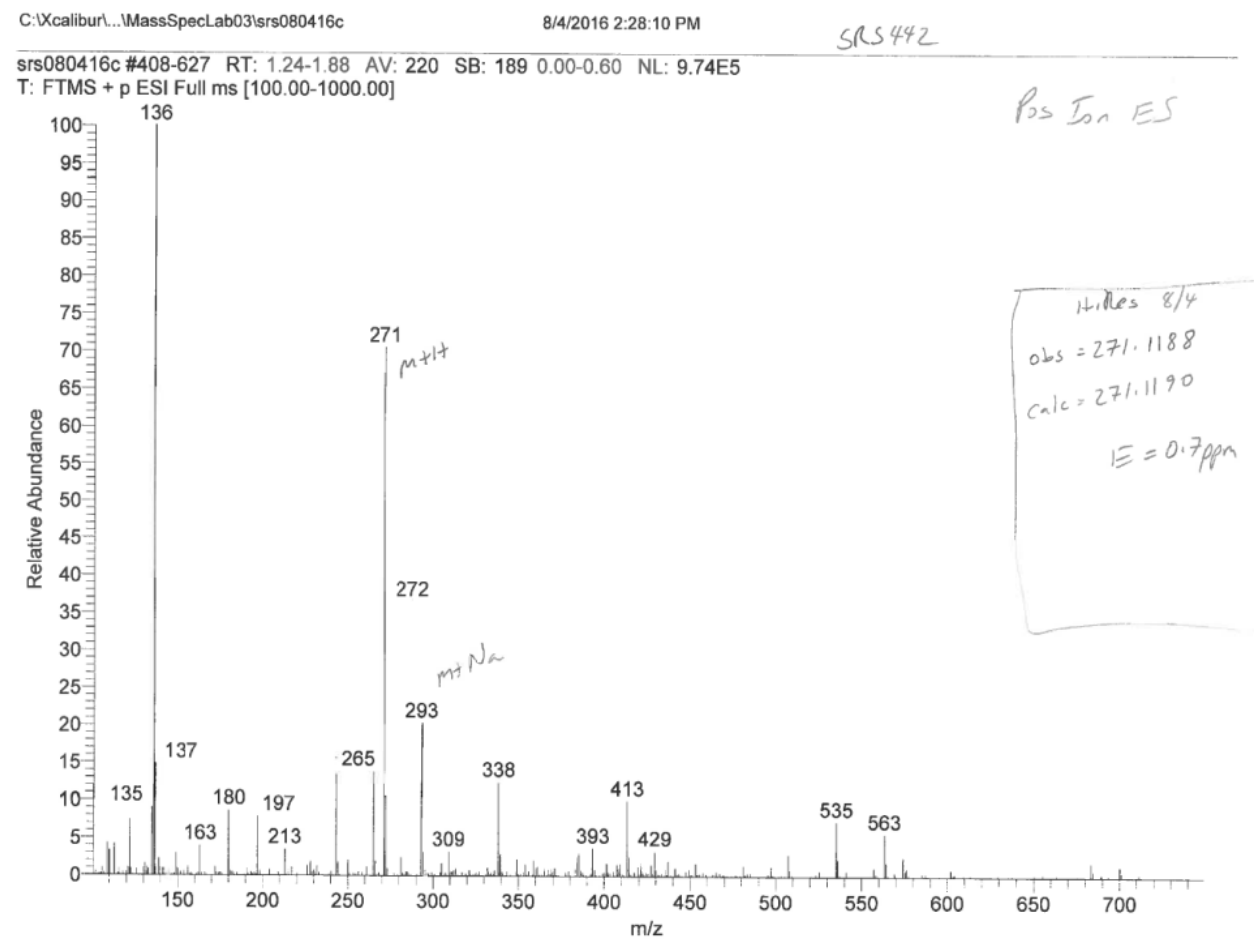

Figure S2. HRMS (DEP) of $o$-DPOA. [M+] calculated, 271.1190 found, 271.1188. 


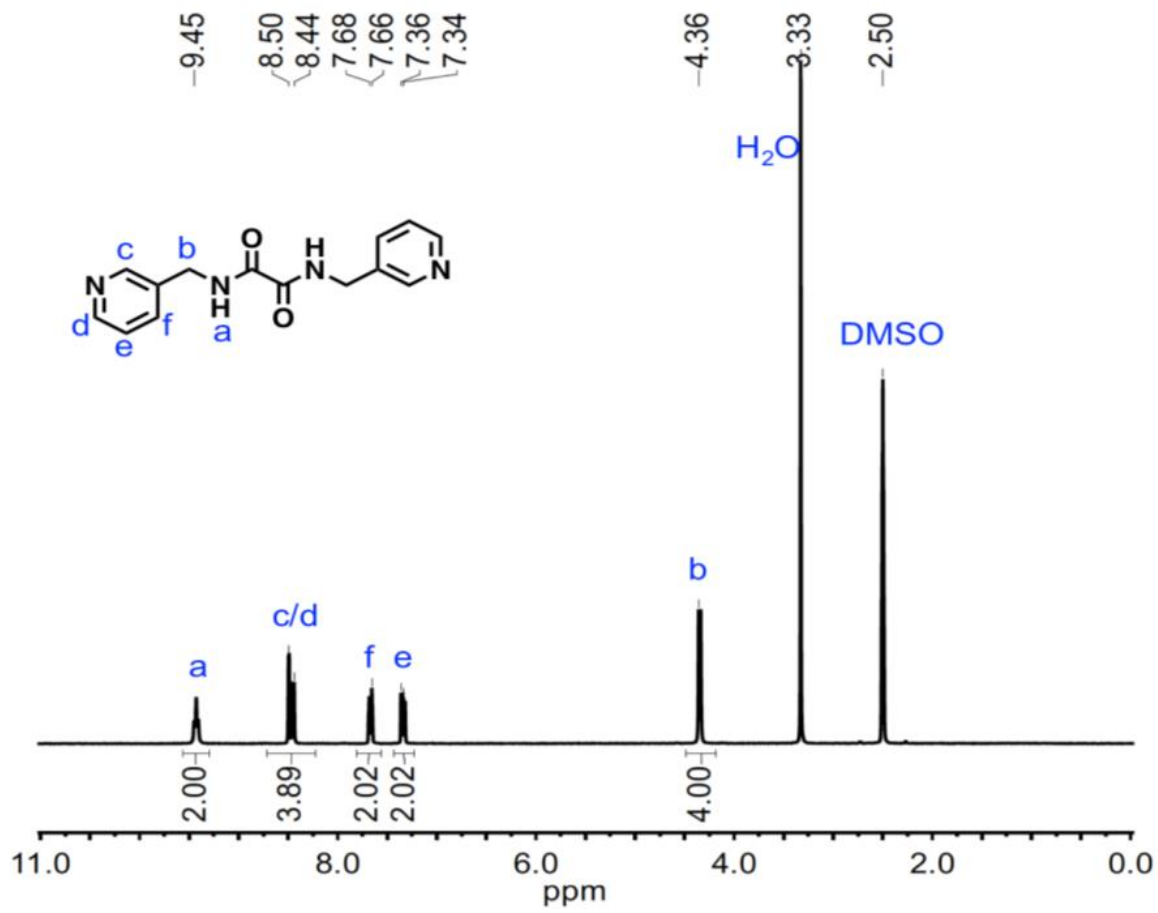

Figure S3. ${ }^{1} \mathrm{H}$ NMR of $m$-DPOA recorded in DMSO-d6.

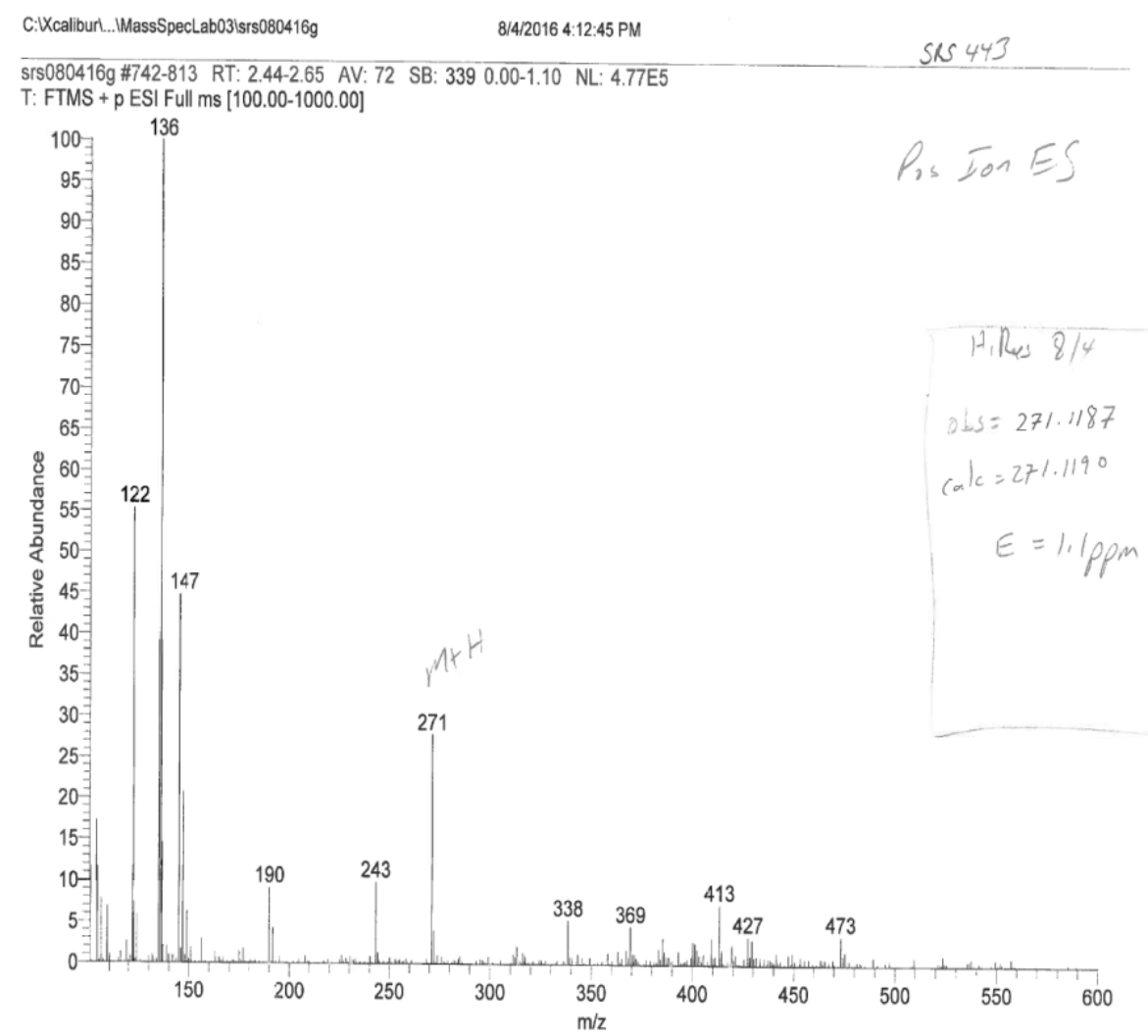

Figure S4. HRMS (DEP) of $m$-DPOA. [M+] calculated, 271.1190 found, 271.1187. 


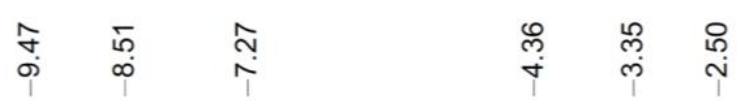
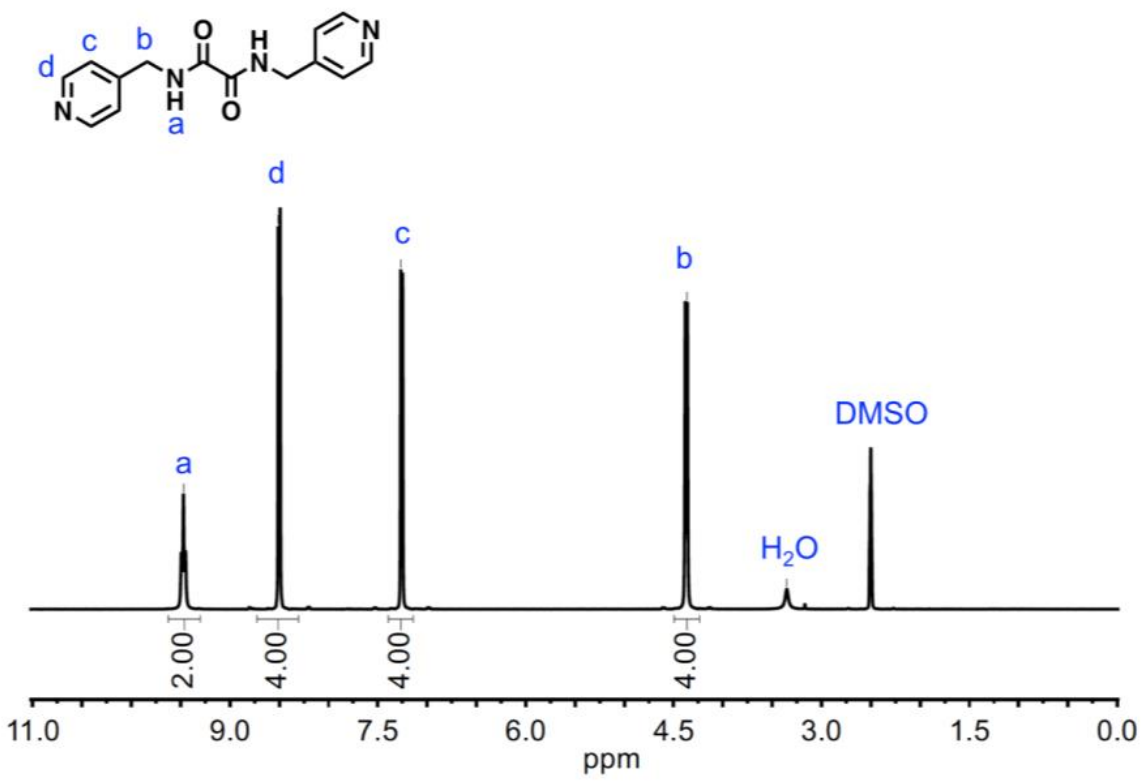

${ }^{1} \mathrm{H}$ NMR of $p$-DPOA recorded in DMSO-d6.

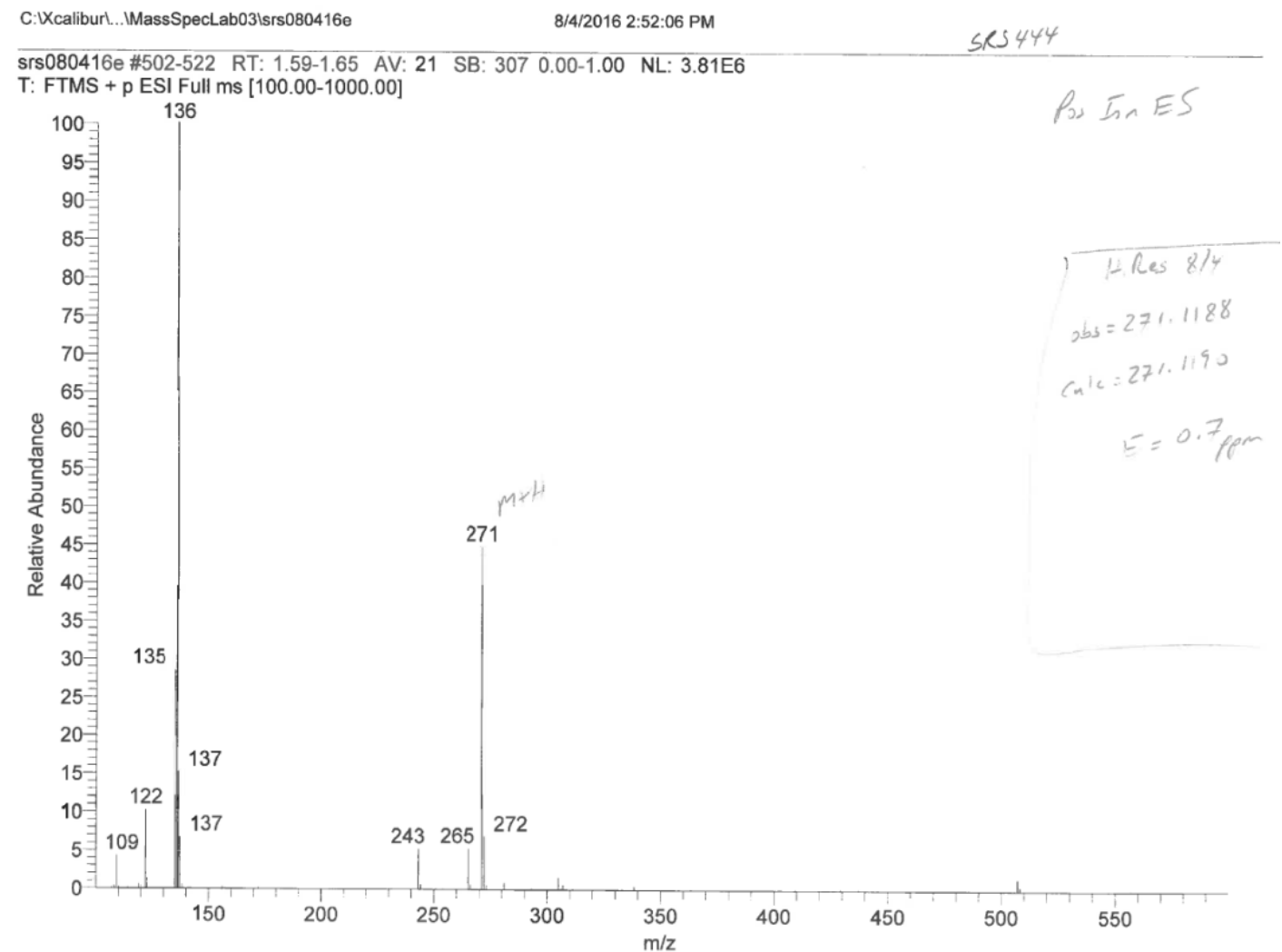

Figure S6. HRMS (DEP) of $p$-DPOA. [M+] calculated, 271.1190 found, 271.1188. 
Table S1. Summary of crystal growth and habit.

\begin{tabular}{|c|c|c|c|c|c|c|}
\hline Crystal & $\begin{array}{l}\text { Crystallization } \\
\text { Method }\end{array}$ & $\begin{array}{c}\text { Ratio } \\
\text { DPOA:TFDIB }\end{array}$ & $\begin{array}{l}\text { Space } \\
\text { Group }\end{array}$ & $\begin{array}{l}\text { Crystal } \\
\text { System }\end{array}$ & $\begin{array}{l}\text { Crystal } \\
\text { Habit }\end{array}$ & $\begin{array}{l}\text { Melting } \\
\text { Point }\left({ }^{\circ} \mathrm{C}\right)\end{array}$ \\
\hline$o$-DPOA & $\begin{array}{l}\text { Slow evaporation from } \\
\text { acetonitrile }\end{array}$ & -- & P1 (No. 1) & Triclinic & $\begin{array}{c}\text { Colorless } \\
\text { needles }\end{array}$ & 163 \\
\hline$(o \text {-DPOA })_{2} \bullet o$-TFDIB & $\begin{array}{l}\text { Vapor diffusion from } \\
\mathrm{DMSO} / \mathrm{H}_{2} \mathrm{O}\end{array}$ & $2: 1$ & $P 2_{1} / n$ & Monoclinic & $\begin{array}{l}\text { Colorless flat } \\
\text { needles }\end{array}$ & 161 \\
\hline $\begin{array}{c}o \text {-DPOA } \bullet m \text {-TFDIB } \\
(\mathrm{solv})_{\mathrm{x}}\end{array}$ & $\begin{array}{l}\text { Slow evaporation from } \\
\text { chloroform }\end{array}$ & $1: 1$ & $P 2_{1} / n$ & Monoclinic & $\begin{array}{l}\text { Colorless } \\
\text { needles }\end{array}$ & $144-152$ \\
\hline$(o \text {-DPOA })_{2} \bullet p$-TFDIB & $\begin{array}{l}\text { Slow evaporation from } \\
\text { acetonitrile }\end{array}$ & $2: 1$ & P1 (No. 2) & Triclinic & $\begin{array}{l}\text { Fine } \\
\text { colorless } \\
\text { fibers }\end{array}$ & $186-188$ \\
\hline$o-\mathrm{DPOA} \bullet(p \text {-TFDIB })_{2}$ & $\begin{array}{l}\text { Vapor diffusion from } \\
\mathrm{DMSO} / \mathrm{H}_{2} \mathrm{O}\end{array}$ & $1: 2$ & P1 (No. 2) & Triclinic & $\begin{array}{l}\text { Colorless } \\
\text { needles }\end{array}$ & $176-180$ \\
\hline$m-\mathrm{DPOA} \cdot \mathrm{H}_{2} \mathrm{O}$ & $\begin{array}{l}\text { Slow evaporation from } \\
\text { acetonitrile }\end{array}$ & $1: 1^{[1]}$ & $P 2_{1} / n$ & Monoclinic & $\begin{array}{l}\text { Colorless } \\
\text { needles }\end{array}$ & 198 \\
\hline $\begin{array}{c}m \text {-DPOA } o \text {-TFDIB } \bullet \\
(\text { solv })_{\mathrm{x}}\end{array}$ & $\begin{array}{l}\text { Slow evaporation from } \\
\text { tetrahydrofuran }\end{array}$ & $1: 1$ & $P 2_{1} / n$ & Monoclinic & $\begin{array}{l}\text { Colorless } \\
\text { needles }\end{array}$ & $97-120$ \\
\hline$m$-DPOA $\bullet m$-TFDIB & $\begin{array}{l}\text { Slow evaporation from } \\
\text { t-butanol }\end{array}$ & $1: 1$ & P1 (No. 2) & Triclinic & $\begin{array}{l}\text { Colorless } \\
\text { needles }\end{array}$ & $170-175$ \\
\hline $\begin{array}{c}m-\mathrm{DPOA} \bullet(m-\mathrm{TFDIB})_{2} \bullet \\
\text { DMSO }\end{array}$ & $\begin{array}{l}\text { Vapor diffusion from } \\
\text { DMSO/ } \mathrm{H}_{2} \mathrm{O}\end{array}$ & $1: 2: 1^{[2]}$ & P1 (No. 2) & Triclinic & $\begin{array}{l}\text { Colorless } \\
\text { needles }\end{array}$ & -- \\
\hline$m$-DPOA $\bullet p$-TFDIB & $\begin{array}{l}\text { Vapor diffusion from } \\
\text { DMSO/ } \mathrm{H}_{2} \mathrm{O}\end{array}$ & $1: 1$ & P1 (No. 2) & Triclinic & $\begin{array}{l}\text { Colorless } \\
\text { needles }\end{array}$ & $188-190$ \\
\hline$p$-DPOA & $\begin{array}{l}\text { Slow evaporation from } \\
\text { tetrahydrofuran }\end{array}$ & -- & $P 2_{1} / n$ & Monoclinic & $\begin{array}{c}\text { Colorless flat } \\
\text { needles }\end{array}$ & 215 \\
\hline$p$-DPOA $\bullet-$-TFDIB & $\begin{array}{l}\text { Slow evaporation from } \\
\text { methanol }\end{array}$ & $1: 1$ & P1 (No. 2) & Triclinic & $\begin{array}{l}\text { Colorless } \\
\text { needles }\end{array}$ & $190(\text { dec. })^{[3]}$ \\
\hline$p$-DPOA $\bullet m$-TFDIB & $\begin{array}{l}\text { Slow evaporation from } \\
\text { acetonitrile }\end{array}$ & $1: 1$ & P1 (No. 2) & Triclinic & $\begin{array}{l}\text { Colorless } \\
\text { needles }\end{array}$ & $179-210$ \\
\hline$p$-DPOA $\bullet(m \text {-TFDIB })_{2}$ & $\begin{array}{l}\text { Vapor diffusion from } \\
\text { DMSO/ } \mathrm{H}_{2} \mathrm{O}\end{array}$ & $1: 2$ & P1 (No. 2) & Triclinic & $\begin{array}{l}\text { Colorless } \\
\text { needles }\end{array}$ & 120 \\
\hline$p$-DPOA $\bullet p$-TFDIB & $\begin{array}{l}\text { Vapor diffusion from } \\
\mathrm{DMSO} / \mathrm{H}_{2} \mathrm{O}\end{array}$ & $1: 1$ & P1 (No. 2) & Triclinic & $\begin{array}{l}\text { Colorless } \\
\text { needles }\end{array}$ & 204-206 \\
\hline
\end{tabular}


Table S2. Summary of HB and XB interactions for the $o$-DPOA series.

\begin{tabular}{|c|c|c|c|}
\hline Crystal & $\begin{array}{c}\mathbf{D} \cdots \mathbf{A} \\
\text { Interactions }\end{array}$ & $\begin{array}{c}\text { Distance } \\
(\AA)\end{array}$ & Angle $\left({ }^{\circ}\right)$ \\
\hline$o$-DPOA & $\mathrm{N}-\mathrm{H} \cdots \mathrm{O}$ & $\begin{array}{l}2.849(3) \\
2.837(3) \\
2.853(2) \\
2.852(2)\end{array}$ & $\begin{array}{l}153(3) \\
150(3) \\
154(3) \\
156(3)\end{array}$ \\
\hline$(o \text {-DPOA })_{2} \bullet o$-TFDIB & $\mathrm{N}-\mathrm{H} \cdots \mathrm{O}$ & $\begin{array}{c}2.862(3) \\
2.878(3) \\
2.851(3) \\
2.852(3) \\
2.931(6) \\
3.012(7) \\
2.905(12) \\
2.733(12)\end{array}$ & $\begin{array}{l}154(3) \\
150(3) \\
152(3) \\
159(3) \\
172(2) \\
173(2) \\
173(3) \\
174(3)\end{array}$ \\
\hline $\begin{array}{c}o \text {-DPOA } \bullet m \text {-TFDIB• } \\
(\mathrm{solv})_{\mathrm{x}}\end{array}$ & $\begin{array}{c}\mathrm{N}-\mathrm{H} \cdots \mathrm{O} \\
\mathrm{N} \cdots \mathrm{I}\end{array}$ & $\begin{array}{l}2.836(4) \\
2.846(4) \\
2.882(3) \\
2.930(3)\end{array}$ & $\begin{array}{c}152(4) \\
154(2) \\
174(11) \\
175(5)\end{array}$ \\
\hline $\begin{array}{l}(o \text {-DPOA })_{2} \bullet p \text {-TFDIB } \\
\text { from acetonitrile }\end{array}$ & $\begin{array}{c}\mathrm{N}-\mathrm{H} \cdots \mathrm{O} \\
\mathrm{N} \cdots \mathrm{I}\end{array}$ & $\begin{array}{l}2.861(3) \\
2.846(3) \\
2.820(2)\end{array}$ & $\begin{array}{l}159(3) \\
157(3) \\
176(8)\end{array}$ \\
\hline $\begin{array}{c}o \text {-DPOA } \bullet(p \text {-TFDIB })_{2} \\
\text { from DMSO }\end{array}$ & $\begin{array}{c}\mathrm{N}-\mathrm{H} \cdots \mathrm{O} \\
\mathrm{N} \cdots \mathrm{I}\end{array}$ & $\begin{array}{l}2.842(5) \\
2.790(4)\end{array}$ & $\begin{array}{l}162(6) \\
176(2)\end{array}$ \\
\hline
\end{tabular}


Table S3. Summary of HB and XB interactions for the $m$-DPOA series.

\begin{tabular}{|c|c|c|c|}
\hline Crystal & $\begin{array}{c}\mathbf{D} \cdots \mathbf{A} \\
\text { Interactions }\end{array}$ & Distance ( $\AA$ ) & Angle $\left({ }^{\circ}\right)$ \\
\hline$m-\mathrm{DPOA} \cdot \mathrm{H}_{2} \mathrm{O}$ & $\begin{array}{l}\mathrm{N}-\mathrm{H} \cdots \mathrm{O} \\
\mathrm{O}-\mathrm{H} \cdots \mathrm{N} \\
\mathrm{O}-\mathrm{H} \cdots \mathrm{O}\end{array}$ & $\begin{array}{c}2.822(13) \\
2.801(13) \\
2.795(13) \\
2.837(8)\end{array}$ & $\begin{array}{c}156(15) \\
151(14) \\
168(17) \\
170(2)\end{array}$ \\
\hline$m$-DPOA $\bullet o-\mathrm{TFDIB} \bullet(\text { solv })_{\mathrm{x}}$ & $\begin{array}{c}\mathrm{N}-\mathrm{H} \cdots \mathrm{O} \\
\mathrm{N} \cdots \mathrm{I}\end{array}$ & $\begin{array}{c}2.868(2) \\
2.866(2) \\
2.898(18) \\
2.821(19)\end{array}$ & $\begin{array}{l}155(2) \\
155(2) \\
171(7) \\
176(7)\end{array}$ \\
\hline$m$-DPOA $\bullet m$-TFDIB & $\begin{array}{c}\mathrm{N}-\mathrm{H} \cdots \mathrm{O} \\
\mathrm{N} \cdots \mathrm{I}\end{array}$ & $\begin{array}{l}2.862(13) \\
2.864(13) \\
2.832(11)\end{array}$ & $\begin{array}{c}157(17) \\
156(16) \\
173(5)\end{array}$ \\
\hline$m$-DPOA $\bullet(m-\mathrm{TFDIB})_{2} \bullet \mathrm{DMSO}$ & $\begin{array}{c}\mathrm{N}-\mathrm{H} \cdots \mathrm{O} \\
\mathrm{N} \cdots \mathrm{I} \\
\mathrm{C}=\mathrm{O} \cdots \mathrm{I} \\
\mathrm{S}=\mathrm{O} \cdots \mathrm{I}\end{array}$ & $\begin{array}{l}2.807(4) \\
2.814(4) \\
2.759(3) \\
2.757(4) \\
3.196(3) \\
2.850(4)\end{array}$ & $\begin{array}{l}153(4) \\
152(4) \\
174(1) \\
174(1) \\
159(1) \\
177(1)\end{array}$ \\
\hline$m$-DPOA $\bullet p$-TFDIB & $\begin{array}{c}\mathrm{N}-\mathrm{H} \cdots \mathrm{O} \\
\mathrm{N} \cdots \mathrm{I}\end{array}$ & $\begin{array}{l}2.831(15) \\
2.854(12)\end{array}$ & $\begin{array}{c}151(16) \\
172(5)\end{array}$ \\
\hline
\end{tabular}


Table S4. Summary of HB and XB interactions for the $p$-DPOA series.

\begin{tabular}{|c|c|c|c|}
\hline Crystal & $\begin{array}{c}\mathbf{D} \cdots \mathbf{A} \\
\text { Interactions }\end{array}$ & Distance ( $\AA$ ) & Angle ( $\left.{ }^{\circ}\right)$ \\
\hline$p$-DPOA & $\mathrm{N}-\mathrm{H} \cdots \mathrm{O}$ & $\begin{array}{l}2.913(17) \\
2.905(18) \\
2.924(18) \\
2.886(17)\end{array}$ & $\begin{array}{l}154(16) \\
159(15) \\
162(16) \\
156(15)\end{array}$ \\
\hline$p$-DPOA $\bullet$-TFDIB & $\mathrm{N}-\mathrm{H} \cdots \mathrm{O}$ & $\begin{array}{l}2.755(7) \\
2.831(8) \\
2.802(8) \\
2.896(8) \\
2.992(6) \\
2.997(6) \\
2.943(6) \\
2.938(6)\end{array}$ & $\begin{array}{c}151(6) \\
137(6) \\
160(8) \\
146(7) \\
165(3) 3 b \\
166(3) 3 a \\
171(3) 4 a \\
170(3) 4 b\end{array}$ \\
\hline $\begin{array}{l}p \text {-DPOA } \bullet m \text {-TFDIB } \\
\text { from acetonitrile }\end{array}$ & $\begin{array}{c}\mathrm{N}-\mathrm{H} \cdots \mathrm{O} \\
\mathrm{N} \cdots \mathrm{I}\end{array}$ & $\begin{array}{l}2.819(3) \\
2.879(3) \\
2.833(2) \\
2.806(3)\end{array}$ & $\begin{array}{c}154(3) \\
161(3) \\
173(9) \\
178(10)\end{array}$ \\
\hline $\begin{array}{l}p \text {-DPOA } \bullet(m-\mathrm{TFDIB})_{2} \\
\text { from DMSO }\end{array}$ & $\begin{array}{c}\mathrm{N}-\mathrm{H} \cdots \mathrm{O} \\
\mathrm{N} \cdots \mathrm{I} \\
\mathrm{O} \cdots \mathrm{I}\end{array}$ & $\begin{array}{l}2.836(3) \\
2.787(3) \\
2.777(2) \\
2.736(2) \\
3.005(2)\end{array}$ & $\begin{array}{l}149(3) \\
157(3) \\
174(9) \\
174(9) \\
178(8)\end{array}$ \\
\hline$p$-DPOA $\bullet p$-TFDIB & $\begin{array}{c}\mathrm{N}-\mathrm{H} \cdots \mathrm{O} \\
\mathrm{N} \cdots \mathrm{I}\end{array}$ & $\begin{array}{c}2.895(2) \\
2.909(2) \\
2.789(18) \\
2.833(18)\end{array}$ & $\begin{array}{l}162(2) \\
160(2) \\
170(7) \\
168(7)\end{array}$ \\
\hline
\end{tabular}




\section{Structure, crystal data, and refinement for $o$-DPOA}

(A)

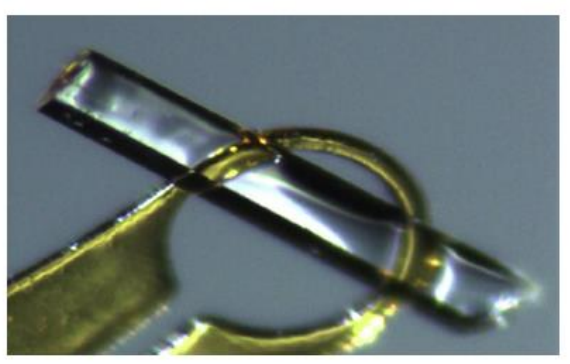

(B)

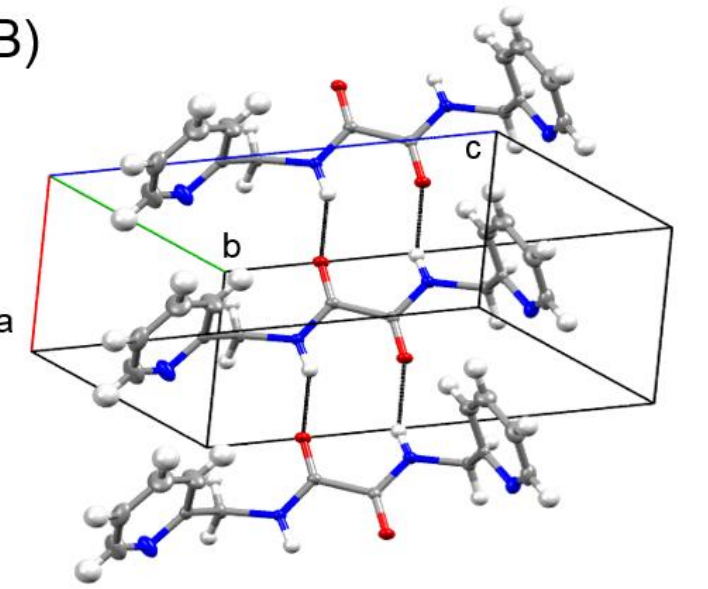

(C)

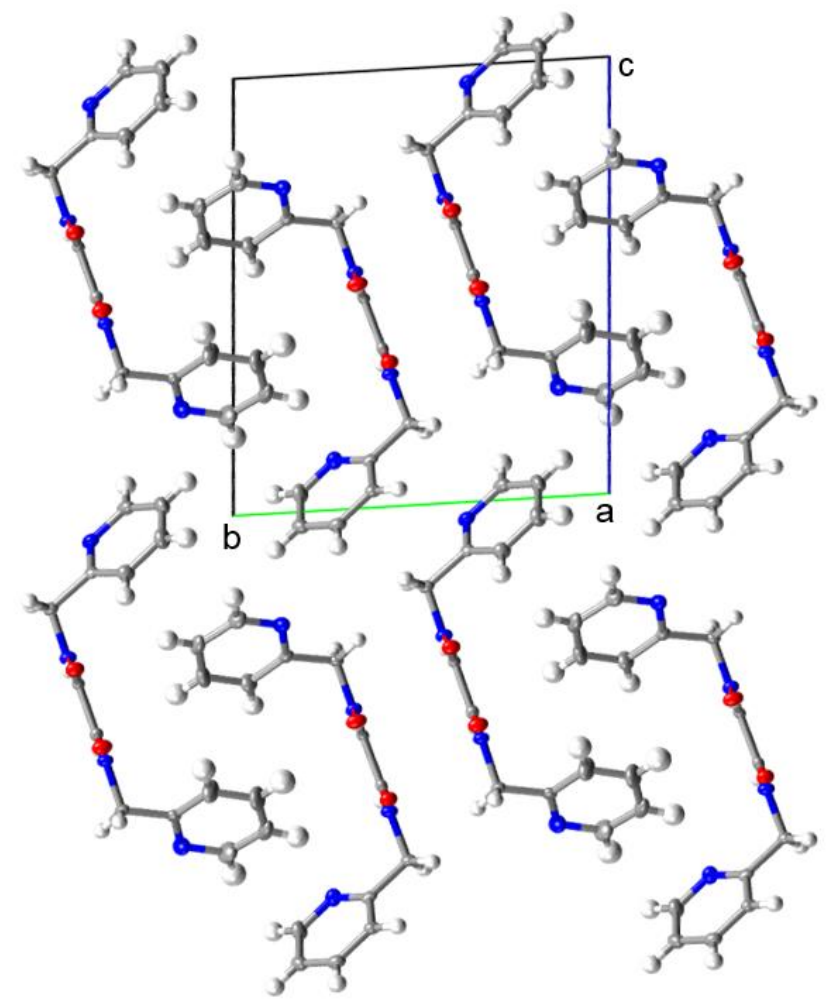

Figure S7. SC-XRD data of $o$-DPOA. (A) Data crystal. (B) DPOA molecules are organized through chains of oxalamide HBs along the crystallographic $a$-axis ([100]). (C) View down the $a$-axis showing the packing along the $b c$ plane. 
Table S5. Crystal data and structure refinement for $o$-DPOA

\begin{tabular}{|c|c|}
\hline CCDC Identification code & CCDC 1921257 \\
\hline Empirical formula & $\mathrm{C}_{14} \mathrm{H}_{14} \mathrm{~N}_{4} \mathrm{O}_{2}$ \\
\hline Formula weight & 270.29 \\
\hline Temperature/K & $100(2)$ \\
\hline Crystal system & triclinic \\
\hline Space group & P1 \\
\hline $\mathrm{a} / \AA$ & $5.0704(3)$ \\
\hline $\mathrm{b} / \AA$ & $10.5206(5)$ \\
\hline $\mathrm{c} / \AA ̊$ & $12.2017(7)$ \\
\hline$\alpha /^{\circ}$ & $93.309(2)$ \\
\hline$\beta /{ }^{\circ}$ & $92.990(2)$ \\
\hline$\gamma /{ }^{\circ}$ & $91.734(2)$ \\
\hline Volume $/ \AA^{3}$ & $648.55(6)$ \\
\hline Z & 2 \\
\hline$\rho_{\text {calc }} \mathrm{g} / \mathrm{cm}^{3}$ & 1.384 \\
\hline$\mu / \mathrm{mm}^{-1}$ & 0.097 \\
\hline$F(000)$ & 284.0 \\
\hline Crystal size $/ \mathrm{mm}^{3}$ & $0.64 \times 0.12 \times 0.08$ \\
\hline Radiation & $\operatorname{MoK} \alpha(\lambda=0.71073)$ \\
\hline $2 \Theta$ range for data collection ${ }^{\circ}$ & 4.972 to 60.332 \\
\hline Index ranges & $-7 \leq \mathrm{h} \leq 7,-14 \leq \mathrm{k} \leq 14,-17 \leq 1 \leq 17$ \\
\hline Reflections collected & 27336 \\
\hline Independent reflections & $7554\left[R_{\text {int }}=0.0321, R_{\text {sigma }}=0.0382\right]$ \\
\hline Data/restraints/parameters & $7554 / 3 / 378$ \\
\hline Goodness-of-fit on $\mathrm{F}^{2}$ & 1.042 \\
\hline Final $R$ indexes $[I>=2 \sigma(I)]$ & $\mathrm{R}_{1}=0.0406, \mathrm{wR}_{2}=0.0854$ \\
\hline Final $\mathrm{R}$ indexes [all data] & $\mathrm{R}_{1}=0.0545, \mathrm{wR}_{2}=0.0910$ \\
\hline Largest diff. peak/hole / e $\AA^{-3}$ & $0.39 /-0.21$ \\
\hline
\end{tabular}


Refinement details for o-DPOA: The compound crystallizes in the triclinic system. Intensity statistics suggested a centrosymmtric structure. The correct space group was eventually established to be the non-centrosymmetric group $P 1$ (No. 1), but with strong pseudosymmetry. The asymmetric unit consists of two crystallographically independent but chemically similar $\mathrm{C}_{14} \mathrm{H}_{14} \mathrm{~N}_{4} \mathrm{O}_{2}$ molecules, which were numbered identically except for label suffixes A or $\mathrm{B}$. All nonhydrogen atoms were refined with anisotropic displacement parameters. Hydrogen atoms bonded to carbon were located in Fourier difference maps before being placed in geometrically idealized positions and included as riding atoms with $d(\mathrm{C}-\mathrm{H})=0.95 \AA$ and $U$ iso $(\mathrm{H})=1.2 U$ eq $(\mathrm{C})$ for aromatic hydrogen atoms and $d(\mathrm{C}-\mathrm{H})=0.99 \AA$ and $U \mathrm{iso}(\mathrm{H})=1.2 U \mathrm{eq}(\mathrm{C})$ for methylene hydrogens. The four independent hydrogen atoms bonded to nitrogen were located in Fourier difference maps and refined freely. The largest residual electron density peak in the final difference map is $0.39 \mathrm{e}^{-}$ $/ \AA^{3}$, located $0.74 \AA$ from $\mathrm{C} 1 \mathrm{~B}$. Because of the absence of atoms with $Z>8$ in the crystal, no attempt was made to determine the absolute structure.

Pseudosymmetry and space group $\boldsymbol{P}-\mathbf{1}$ : The structure can be solved in the centrosymmetric space group $P-1$ with one independent molecule per asymmetric unit. This model results in high residual factors $(R 1=0.11)$ and disorder in one pyridyl ring, effectively scrambling the nitrogen atom positions. Larger anisotropic displacement parameters for atoms of the apparent disordered ring are also observed. Refinement in space group $P 1$ (No. 1) resolves the pyridyl ring disorder, normalizes the anisotropic displacement parameters and reduces the $R$-values to the reported $R_{1} / \mathrm{wR}_{2}=0.041 / 0.091$. The structure is therefore best interpreted as pseudosymmetric, with opposite orientation of two independent pyridyl rings breaking centrosymmetry. Examination of the $P 1$ structure shows pyridyl rings N3/C4-C8 (A/B) are incompatible with the inversion symmetry relating the remaining atoms of the two independent molecules. Imposition of an inversion center between molecules $\mathrm{A}$ and $\mathrm{B}$ superimposes rings $\mathrm{N} 3 / \mathrm{C} 4-\mathrm{C} 8 \mathrm{~A} / \mathrm{B}$, which differ by a $180^{\circ}$ rotation, resulting in apparent $\mathrm{C} / \mathrm{N}$ disorder and inflated displacement parameters. The larger anisotropic displacement parameters are because of small differences in $\mathrm{C} / \mathrm{N}$ positions between the two oppositely oriented components being absorbed into the ellipsoidal description of atomic displacement. The achievement of (1) a stable refinement with normal ellipsoids and molecular geometries and (2) freely refined hydrogen atoms which give good geometric and atomic parameters is further support for the correctness of the non-centrosymmetric space group. 


\section{Structure, crystal data, and refinement for $(o-D P O A)_{2} \bullet o-T F D I B$}

(A)

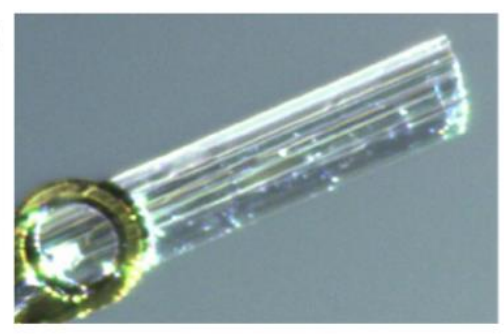

(B)

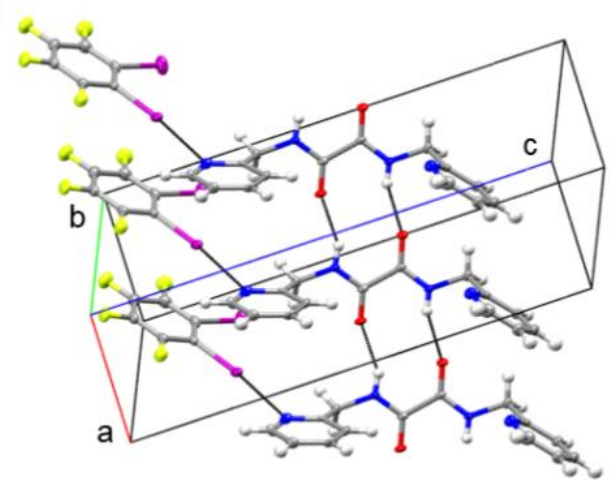

(C)

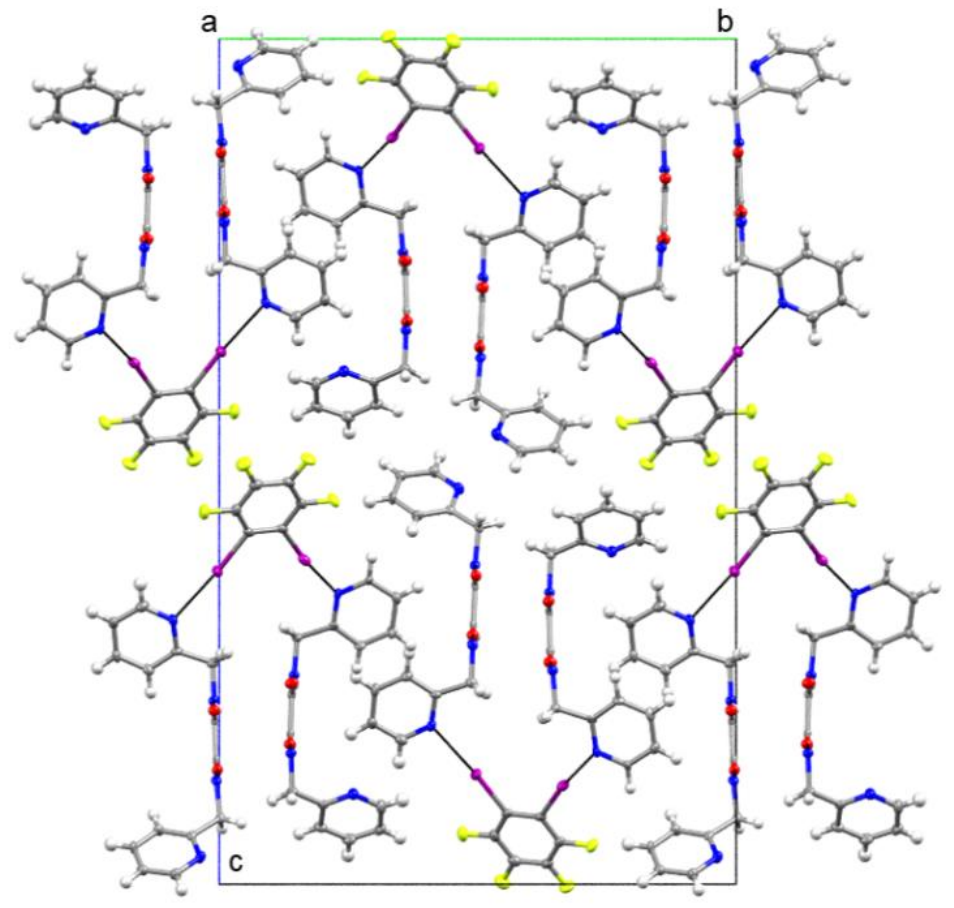

Figure S8. SC-XRD data of $(o \text {-DPOA })_{2} \bullet o$-TFDIB. (A) data crystal (B) Oxalamide HB interactions form chains along the $a$-axis direction while XB interactions between the pyridyl nitrogen and iodine of the TFDIB connect two DPOA molecules (C) View down the $a$-axis showing the packing along the $b c$ plane.

Refinement details for (o-DPOA) $2 \bullet o$-TFDIB: The compound crystallizes in the monoclinic system. The pattern of systematic absences in the intensity data was consistent with the space group $P 2_{1} / n$, which was confirmed by structure solution. The asymmetric unit consists of two crystallographically independent $o-\mathrm{C}_{14} \mathrm{H}_{14} \mathrm{~N}_{4} \mathrm{O}_{2}$ molecules and one $o-\mathrm{C}_{6} \mathrm{~F}_{4} \mathrm{I}_{2}$ molecule. The two crystallographically independent $o-\mathrm{C}_{14} \mathrm{H}_{14} \mathrm{~N}_{4} \mathrm{O}_{2}$ molecules were numbered identically except for label suffixes $\mathrm{A}$ or $\mathrm{B}$. Three of the four pyridyl rings are disordered. The affected rings are C10A-C14A/N4A, C4B-C8B/N3B, and C10B-C14B/N4B. The second disorder components of molecule $A$ and $B$ were given label suffixes $C$ and $D$, respectively. Atoms of ring C4-C8/N3(B/D) are completely superimposed; i.e. the disorder takes the form of an exact $180^{\circ}$ rotation about the $\mathrm{C} 3 \mathrm{~B}-\mathrm{C} 4$ bond. Atoms in the other two disordered rings are not superimposed. Disordered ring occupancies initially refined to, and were subsequently fixed at, 0.5 . The geometries of all disordered pyridyl rings were restrained to be similar to that of the ordered ring C4A-C8A/N4A using SHELX SAME instructions. All non-hydrogen atoms were refined with anisotropic displacement parameters. Hydrogen atoms bonded to carbon were located in Fourier difference maps before being placed in geometrically idealized positions and included as riding atoms with $d(\mathrm{C}-\mathrm{H})=0.95 \AA$ and $U$ iso $(\mathrm{H})=1.2 U$ eq $(\mathrm{C})$ for aromatic hydrogen atoms and $d(\mathrm{C}-\mathrm{H})=0.99 \AA$ and $U$ iso $(\mathrm{H})=1.2 U$ eq $(\mathrm{C})$ for methylene hydrogen atoms. Hydrogen atoms bonded to nitrogen were located in difference Fourier maps. They were refined with similar-distance N-H distance restraints $(\mathrm{SADI})$ and with displacement parameters set at $U$ iso $(\mathrm{H})=1.2 U$ eq $(\mathrm{N})$. The largest residual electron density peak in the final difference map is $0.96 \mathrm{e}^{-/} \AA^{3}$, located $1.06 \AA$ 
Table S6. Crystal data and structure refinement for $(o \text {-DPOA })_{2} \bullet o$-TFDIB

\begin{tabular}{|c|c|}
\hline CCDC Identification code & CCDC 1921258 \\
\hline Empirical formula & $\mathrm{C}_{34} \mathrm{H}_{28} \mathrm{~F}_{4} \mathrm{I}_{2} \mathrm{~N}_{8} \mathrm{O}_{4}$ \\
\hline Formula weight & 942.44 \\
\hline Temperature/K & $100(2)$ \\
\hline Crystal system & monoclinic \\
\hline Space group & $\mathrm{P} 21_{1} / \mathrm{n}$ \\
\hline $\mathrm{a} / \AA$ & $5.0825(2)$ \\
\hline $\mathrm{b} / \AA$ & $20.7599(9)$ \\
\hline $\mathrm{c} / \AA$ & $32.4945(14)$ \\
\hline$\alpha /^{\circ}$ & 90 \\
\hline$\beta /{ }^{\circ}$ & $90.515(2)$ \\
\hline$\gamma /{ }^{\circ}$ & 90 \\
\hline Volume $/ \AA^{3}$ & $3428.4(2)$ \\
\hline Z & 4 \\
\hline$\rho_{\text {calc }} \mathrm{g} / \mathrm{cm}^{3}$ & 1.826 \\
\hline$\mu / \mathrm{mm}^{-1}$ & 1.909 \\
\hline $\mathrm{F}(000)$ & 1848.0 \\
\hline Crystal size $/ \mathrm{mm}^{3}$ & $0.54 \times 0.16 \times 0.02$ \\
\hline Radiation & $\operatorname{MoK} \alpha(\lambda=0.71073)$ \\
\hline $2 \Theta$ range for data collection $/{ }^{\circ}$ & 4.242 to 55.172 \\
\hline Index ranges & $-6 \leq \mathrm{h} \leq 6,-27 \leq \mathrm{k} \leq 27,-42 \leq 1 \leq 42$ \\
\hline Reflections collected & 111510 \\
\hline Independent reflections & $7939\left[\mathrm{R}_{\text {int }}=0.0759, \mathrm{R}_{\text {sigma }}=0.0431\right]$ \\
\hline Data/restraints/parameters & $7939 / 128 / 566$ \\
\hline Goodness-of-fit on $\mathrm{F}^{2}$ & 1.079 \\
\hline Final $R$ indexes $[I>=2 \sigma(I)]$ & $\mathrm{R}_{1}=0.0371, \mathrm{wR}_{2}=0.0618$ \\
\hline Final $\mathrm{R}$ indexes [all data] & $\mathrm{R}_{1}=0.0646, \mathrm{w} \mathrm{R}_{2}=0.0680$ \\
\hline Largest diff. peak/hole / e $\AA^{-3}$ & $0.96 /-0.96$ \\
\hline
\end{tabular}


Structure, crystal data, and refinement for $o-D P O A \bullet m-T F D I B \bullet(s o l v)_{x}$

(A)

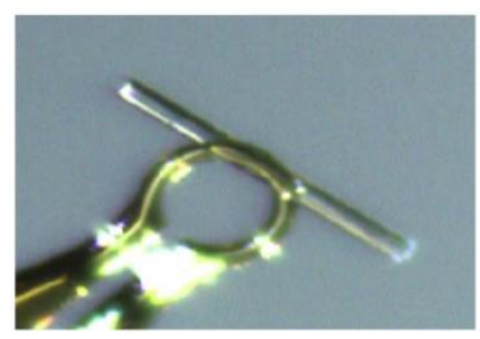

(B)

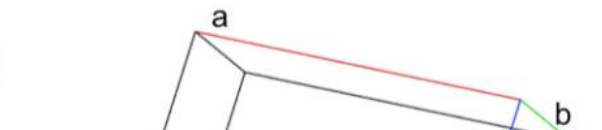

(C)

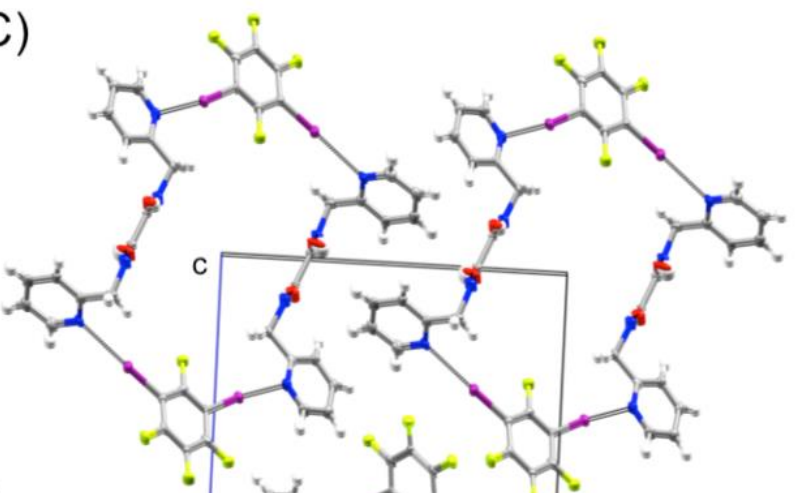

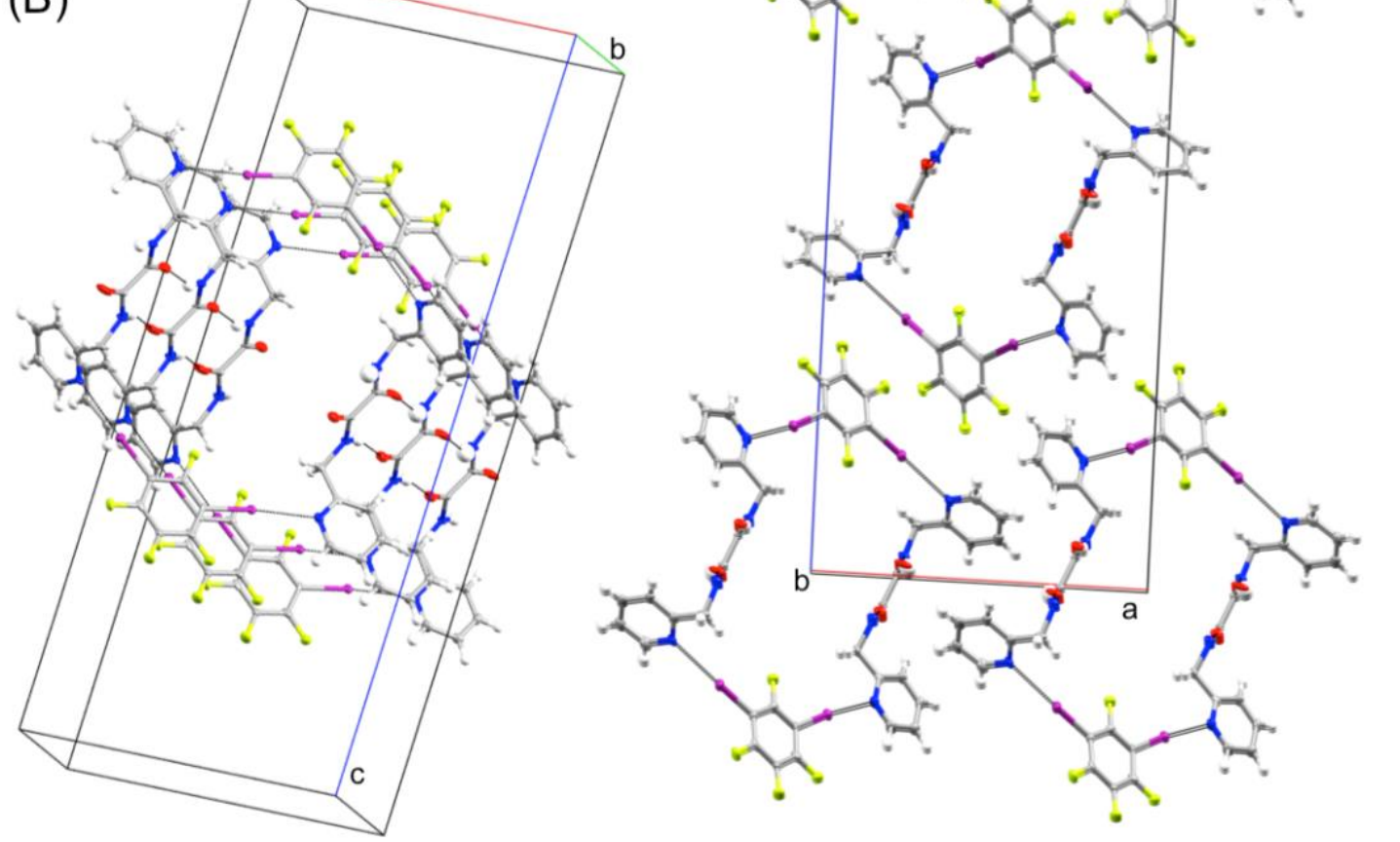

Figure S9. SC-XRD data of $o$-DPOA $\bullet-$ TFDIB $\bullet($ solv)x. (A) Data crystal (B) The DPOA molecules are stacked through chains of HBs while XB interactions with the m-TFDIB molecules result in the formation porous channels down the $b$-axis, disordered solvent was removed using SQUEEZE (C) View down the $b$-axis showing the packing along the $b c$ plane. 
Refinement details for $\boldsymbol{o}$-DPOA $\boldsymbol{m}$-TFDIB $\bullet(s o l v)_{\mathbf{x}}$ : The compound crystallizes in the monoclinic system. The pattern of systematic absences in the intensity data was consistent with the space group $P 2_{1} / n$, which was confirmed by structure solution. The asymmetric unit consists of one $\mathrm{C}_{14} \mathrm{H}_{14} \mathrm{~N}_{4} \mathrm{O}_{2}$ molecule, one $m-\mathrm{C}_{6} \mathrm{~F}_{4} \mathrm{I}_{2}$ molecules and many diffusely distributed electron density peaks which could not be assigned to a reasonable disorder model. The $\mathrm{C}_{14} \mathrm{H}_{14} \mathrm{~N}_{4} \mathrm{O}_{2}$ and $\mathrm{C}_{6} \mathrm{~F}_{4} \mathrm{I}_{2}$ molecules form hollow tubes through $\mathrm{N}(\mathrm{H})$-O hydrogen bonding and $\mathrm{N}-\mathrm{I}$ halogen bonding. The intratube channels are filled with highly disordered species which could not be crystallographically resolved. Trial modeling showed a mostly planar array. Disorder models involving several differently oriented, partially occupied $\mathrm{C}_{6} \mathrm{~F}_{4} \mathrm{I}_{2}$ molecules were attempted but were ultimately unsuccessful. The Squeeze program in PLATON was therefore used to account for these species. ${ }^{5}$ The solvent-accessible volume was calculated to be $315 \AA^{3}$ per unit cell $(13 \%$ of the total cell volume), containing the equivalent of 190 electrons per unit cell. The scattering contribution of this electron density was added to the structure factors computed from the known part of the structure during refinement. The reported crystal density and $F . W$. are calculated from the known part of the structure only. From the electron count derived by Squeeze, the crystallization solvent chloroform is more likely to be present ( 58 electrons, $\sim 1 \mathrm{CHCl}_{3}$ per formula unit) rather than $\sim 1 / 4$ of one $\mathrm{C}_{6} \mathrm{~F}_{4} \mathrm{I}_{2}$ molecule ( 178 electrons). All non-hydrogen atoms were refined with anisotropic displacement parameters. Hydrogen atoms bonded to carbon were located in difference Fourier maps before being placed in geometrically idealized positions and included as riding atoms with $d(\mathrm{C}-\mathrm{H})=0.95 \AA$ and $U \mathrm{iso}(\mathrm{H})=1.2 U \mathrm{eq}(\mathrm{C})$ for aromatic hydrogen atoms and $d(\mathrm{C}-\mathrm{H})=0.99 \AA$ and $U$ iso $(\mathrm{H})=1.2 U \mathrm{eq}(\mathrm{C})$ for methylene hydrogen atoms. The two unique hydrogen atoms bonded to nitrogen were located in difference maps and refined isotropically subject to $d(\mathrm{~N}-\mathrm{H})=0.85(2) \AA$ distance restraints. The largest residual electron density peak in the final difference map is $0.73 \mathrm{e}^{-} / \AA^{3}$, located $0.92 \AA$ from I1. 
Table S7 Crystal data and structure refinement for $o$-DPOA $\bullet m$-TFDIB $\bullet(\text { solv })_{\mathrm{x}}$

\begin{tabular}{|c|c|}
\hline CCDC Identification code & CCDC 1921270 \\
\hline Empirical formula & $\mathrm{C}_{20} \mathrm{H}_{14} \mathrm{~F}_{4} \mathrm{I}_{2} \mathrm{~N}_{2} \mathrm{O}_{2}$ \\
\hline Formula weight & 672.15 \\
\hline Temperature/K & $100(2)$ \\
\hline Crystal system & monoclinic \\
\hline Space group & $\mathrm{P} 2{ }_{1} / \mathrm{n}$ \\
\hline $\mathrm{a} / \AA \AA$ & $14.6616(6)$ \\
\hline $\mathrm{b} / \AA$ & $5.0265(2)$ \\
\hline$c / \AA$ & $32.9128(15)$ \\
\hline$\alpha /{ }^{\circ}$ & 90 \\
\hline$\beta /{ }^{\circ}$ & $90.603(2)$ \\
\hline$\gamma /{ }^{\circ}$ & 90 \\
\hline Volume $/ \AA^{3}$ & $2425.43(18)$ \\
\hline Z & 4 \\
\hline$\rho_{\text {calc }} \mathrm{g} / \mathrm{cm}^{3}$ & 1.841 \\
\hline$\mu / \mathrm{mm}^{-1}$ & 2.647 \\
\hline $\mathrm{F}(000)$ & 1280.0 \\
\hline Crystal size $/ \mathrm{mm}^{3}$ & $0.34 \times 0.02 \times 0.02$ \\
\hline Radiation & $\operatorname{MoK} \alpha(\lambda=0.71073)$ \\
\hline $2 \Theta$ range for data collection ${ }^{\circ}$ & 4.95 to 55.21 \\
\hline Index ranges & $-19 \leq \mathrm{h} \leq 19,-6 \leq \mathrm{k} \leq 6,-42 \leq 1 \leq 42$ \\
\hline Reflections collected & 36562 \\
\hline Independent reflections & $5575\left[\mathrm{R}_{\text {int }}=0.0604, \mathrm{R}_{\text {sigma }}=0.0450\right]$ \\
\hline Data/restraints/parameters & $5575 / 2 / 297$ \\
\hline Goodness-of-fit on $\mathrm{F}^{2}$ & 1.043 \\
\hline Final $R$ indexes $[I>=2 \sigma(I)]$ & $\mathrm{R}_{1}=0.0312, \mathrm{wR}_{2}=0.0538$ \\
\hline Final $\mathrm{R}$ indexes [all data] & $\mathrm{R}_{1}=0.0472, \mathrm{wR}_{2}=0.0572$ \\
\hline Largest diff. peak/hole / e $\AA^{-3}$ & $0.73 /-0.79$ \\
\hline
\end{tabular}




\section{Structure, crystal data, and refinement for $(o \text {-DPOA })_{2} \bullet p$-TFDIB}
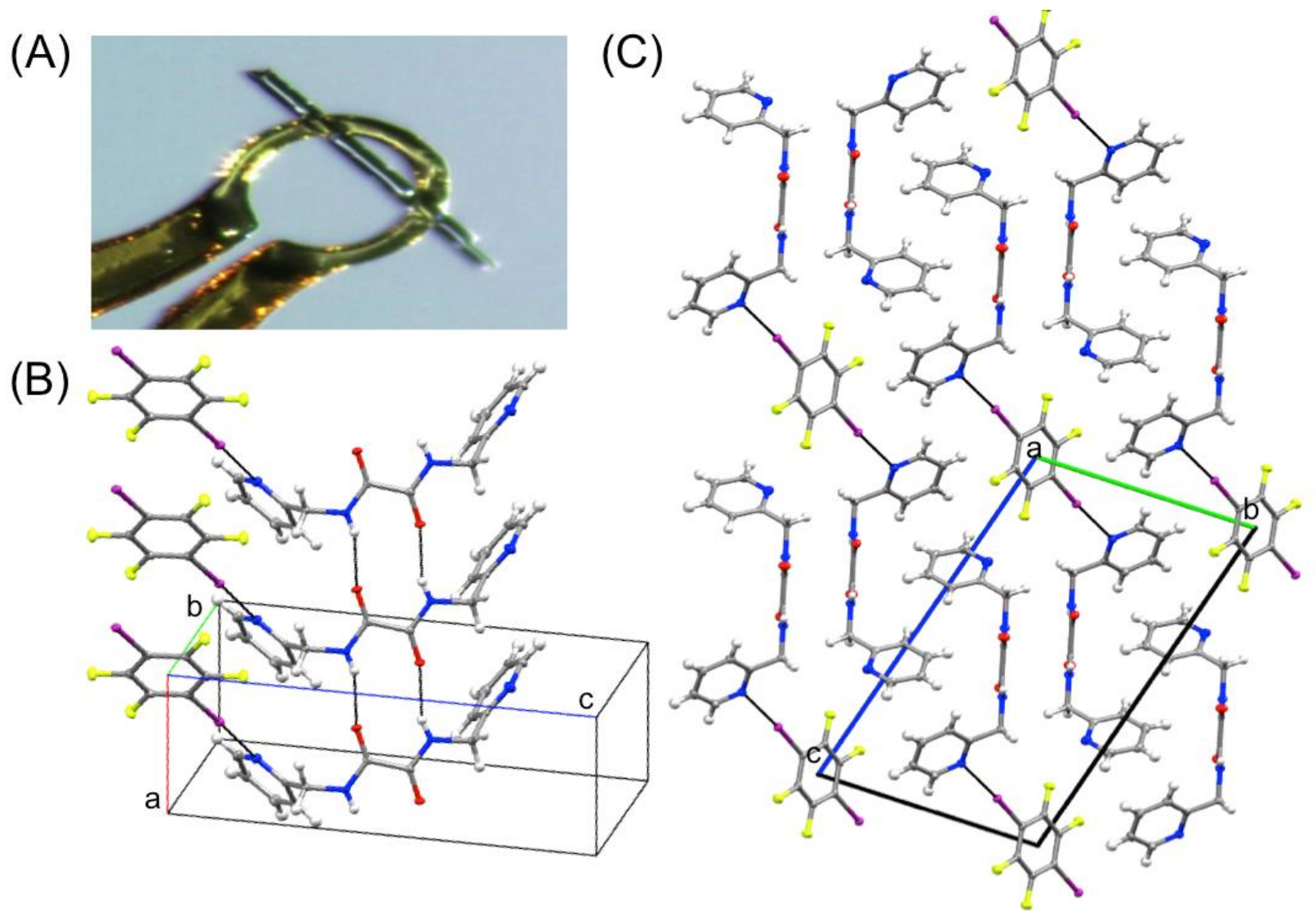

Figure S10. SC-XRD data of $(o \text {-DPOA })_{2} \bullet p$-TFDIB. (A) Data crystal. (B) DPOA molecules are organized through chains of HBs down the crystallographic $a$-axis while a single TFDIB molecules connects two DPOA molecules through XB interactions. (C) View down the $a$-axis showing the packing along the $b c$ plane.

Refinement details for $(\boldsymbol{o} \text {-DPOA })_{2} \bullet \boldsymbol{p}$-TFDIB: The compound crystallizes in the triclinic system. The space group $P-1$ (No. 2) was confirmed by structure solution. The asymmetric unit consists of one $\mathrm{C}_{14} \mathrm{H}_{14} \mathrm{~N}_{4} \mathrm{O}_{2}$ molecule and half of one para- $\mathrm{C}_{6} \mathrm{~F}_{4} \mathrm{I}_{2}$ molecule. The para- $\mathrm{C}_{6} \mathrm{~F}_{4} \mathrm{I}_{2}$ molecule is located on a crystallographic inversion center. All non-hydrogen atoms were refined with anisotropic displacement parameters. Hydrogen atoms bonded to carbon were located in Fourier difference maps before being placed in geometrically idealized positions and included as riding atoms with $d(\mathrm{C}-\mathrm{H})=0.95 \AA$ and $U$ iso $(\mathrm{H})=1.2 U$ eq $(\mathrm{C})$ for aromatic hydrogen atoms and $d(\mathrm{C}-\mathrm{H})=0.99 \AA$ and $U$ iso $(\mathrm{H})=1.2 \operatorname{Ueq}(\mathrm{C})$ for methylene hydrogens. The two nitrogen-bound hydrogen atoms were located in difference maps. Their atomic coordinates were refined freely; displacement parameters were treated as riding with $U$ iso $(\mathrm{H})=1.2 U$ eq $(\mathrm{N})$. The largest residual electron density peak in the final difference map is $0.61 \mathrm{e}^{-/} \AA^{3}$, located $0.76 \AA$ from $\mathrm{C} 21$. 
Table S8. Crystal data and structure refinement for $(o \text {-DPOA })_{2} \bullet p$-TFDIB in acetonitrile.

\begin{tabular}{|c|c|}
\hline CCDC Identification code & CCDC 1921259 \\
\hline Empirical formula & $\mathrm{C}_{34} \mathrm{H}_{28} \mathrm{~F}_{4} \mathrm{I}_{2} \mathrm{~N}_{8} \mathrm{O}_{4}$ \\
\hline Formula weight & 942.44 \\
\hline Temperature/K & $100(2)$ \\
\hline Crystal system & triclinic \\
\hline Space group & $\mathrm{P}-1$ \\
\hline $\mathrm{a} / \AA \AA$ & $5.0514(2)$ \\
\hline $\mathrm{b} / \AA$ & $10.3013(4)$ \\
\hline $\mathrm{c} / \AA$ & $17.1732(8)$ \\
\hline$\alpha /^{\circ}$ & $106.3730(10)$ \\
\hline$\beta /{ }^{\circ}$ & $90.2430(10)$ \\
\hline$\gamma /{ }^{\circ}$ & $93.6050(10)$ \\
\hline Volume $/ \AA^{3}$ & $855.46(6)$ \\
\hline Z & 1 \\
\hline$\rho_{\text {calc }} \mathrm{g} / \mathrm{cm}^{3}$ & 1.829 \\
\hline$\mu / \mathrm{mm}^{-1}$ & 1.913 \\
\hline $\mathrm{F}(000)$ & 462.0 \\
\hline Crystal size $/ \mathrm{mm}^{3}$ & $0.38 \times 0.04 \times 0.02$ \\
\hline Radiation & $\operatorname{MoK} \alpha(\lambda=0.71073)$ \\
\hline $2 \Theta$ range for data collection ${ }^{\circ}$ & 4.172 to 55.416 \\
\hline Index ranges & $-6 \leq \mathrm{h} \leq 6,-13 \leq \mathrm{k} \leq 13,-22 \leq 1 \leq 22$ \\
\hline Reflections collected & 26612 \\
\hline Independent reflections & $3986\left[\mathrm{R}_{\text {int }}=0.0492, \mathrm{R}_{\text {sigma }}=0.0453\right]$ \\
\hline Data/restraints/parameters & $3986 / 0 / 242$ \\
\hline Goodness-of-fit on $\mathrm{F}^{2}$ & 1.032 \\
\hline Final $R$ indexes $[\mathrm{I}>=2 \sigma(\mathrm{I})]$ & $\mathrm{R}_{1}=0.0269, \mathrm{wR}_{2}=0.0462$ \\
\hline Final $\mathrm{R}$ indexes [all data] & $\mathrm{R}_{1}=0.0406, \mathrm{wR}_{2}=0.0485$ \\
\hline Largest diff. peak/hole / e $\AA^{-3}$ & $0.61 /-0.61$ \\
\hline
\end{tabular}




\section{Structure, crystal data, and refinement for $o$-DPOA $\bullet(p \text {-TFDIB })_{2}$}

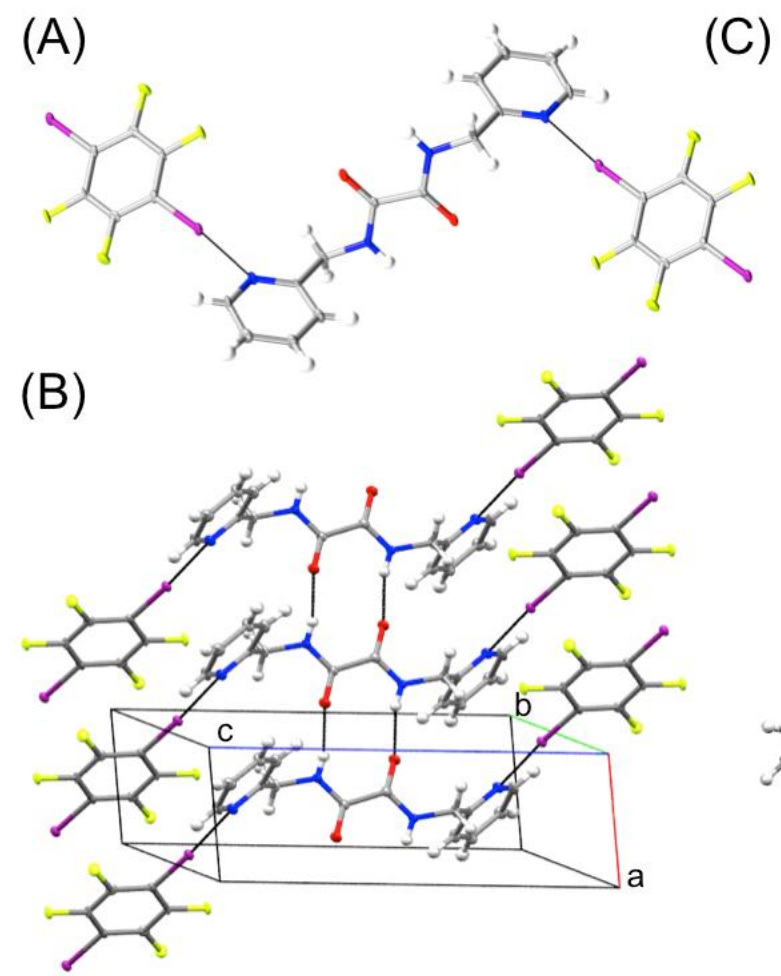

(C)

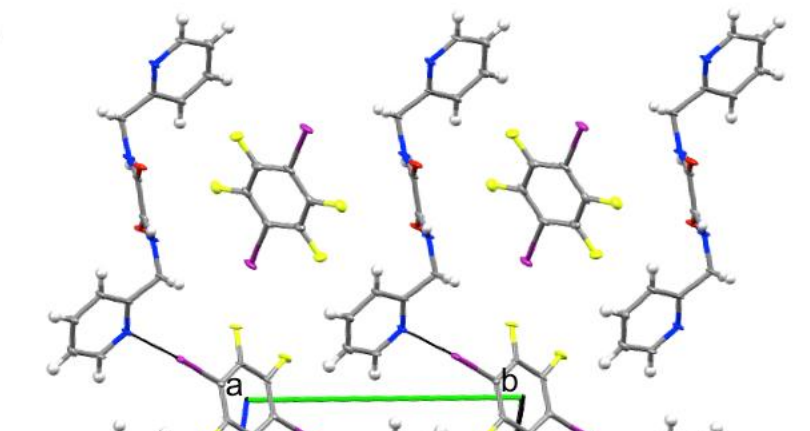

Figure S11. SC-XRD data of $o$-DPOA $\bullet(p$-TFDIB) 2 . (A) Close up of $\mathrm{N} \cdots$ I XB interactions. (B) Chains of HBs assemble the DPOA molecules along the crystallographic $a$-axis which form infinite chains of XBs with the TFDIBs along the $b c$-plane. (C) View down the $a$-axis showing the packing along the $b c$ plane and encapsulated TFDIB molecules

Refinement details for $\boldsymbol{o}$-DPOA $\bullet(\boldsymbol{p} \text {-TFDIB })_{2}$ : The compound crystallizes in the triclinic system. The space group $P-1$ (No. 2) was confirmed by structure solution. The asymmetric unit consists of half of one $\mathrm{C}_{14} \mathrm{H}_{14} \mathrm{~N}_{4} \mathrm{O}_{2}$ molecule, and half each of two independent $\mathrm{C}_{6} \mathrm{~F}_{4} \mathrm{I}_{2}$ molecules. All species are located on crystallographic inversion centers. All non-hydrogen atoms were refined with anisotropic displacement parameters. Hydrogen atoms bonded to carbon were located in Fourier difference maps before being placed in geometrically idealized positions and included as riding atoms with $d(\mathrm{C}-\mathrm{H})=0.95 \AA$ and $U$ iso $(\mathrm{H})=1.2 U$ eq $(\mathrm{C})$ for aromatic hydrogen atoms and $d(\mathrm{C}-\mathrm{H})=0.99 \AA$ and $U \mathrm{iso}(\mathrm{H})=1.2 U \mathrm{eq}(\mathrm{C})$ for methylene hydrogens. The unique nitrogen-bound hydrogen atom $\mathrm{H} 1$ was located in a difference map. Its atomic coordinates were refined freely; its displacement parameter was treated as riding with $U$ iso $(\mathrm{H})=1.2 U$ eq $(\mathrm{N})$. The largest residual electron density peak in the final difference map is $1.32 \mathrm{e}^{-} / \AA^{3}$, located $0.96 \AA$ from $\mathrm{I} 2$. 
Table S9. Crystal data and structure refinement for $o$-DPOA $\bullet(p \text {-TFDIB })_{2}$ in DMSO.

\begin{tabular}{|c|c|}
\hline CCDC Identification code & CCDC 1921260 \\
\hline Empirical formula & $\mathrm{C}_{26} \mathrm{H}_{14} \mathrm{~F}_{8} \mathrm{I}_{4} \mathrm{~N}_{4} \mathrm{O}_{2}$ \\
\hline Formula weight & 1074.01 \\
\hline Temperature/K & $100(2)$ \\
\hline Crystal system & triclinic \\
\hline Space group & $\mathrm{P}-1$ \\
\hline $\mathrm{a} / \AA$ & $4.9926(4)$ \\
\hline $\mathrm{b} / \AA$ & $10.1657(9)$ \\
\hline $\mathrm{c} / \AA$ & $15.1913(13)$ \\
\hline$\alpha /^{\circ}$ & $98.651(3)$ \\
\hline$\beta /^{\circ}$ & $96.826(3)$ \\
\hline$\gamma /{ }^{\circ}$ & $95.058(3)$ \\
\hline Volume $/ \AA^{3}$ & $752.40(11)$ \\
\hline $\mathrm{Z}$ & 1 \\
\hline$\rho_{\text {calc }} \mathrm{g} / \mathrm{cm}^{3}$ & 2.370 \\
\hline$\mu / \mathrm{mm}^{-1}$ & 4.224 \\
\hline $\mathrm{F}(000)$ & 498.0 \\
\hline Crystal size $/ \mathrm{mm}^{3}$ & $0.18 \times 0.03 \times 0.02$ \\
\hline Radiation & $\operatorname{MoK} \alpha(\lambda=0.71073)$ \\
\hline $2 \Theta$ range for data collection $/{ }^{\circ}$ & 4.526 to 55.45 \\
\hline Index ranges & $-6 \leq \mathrm{h} \leq 6,-13 \leq \mathrm{k} \leq 13,-19 \leq 1 \leq 19$ \\
\hline Reflections collected & 26162 \\
\hline Independent reflections & $3530\left[\mathrm{R}_{\text {int }}=0.0784, \mathrm{R}_{\text {sigma }}=0.0435\right]$ \\
\hline Data/restraints/parameters & $3530 / 0 / 202$ \\
\hline Goodness-of-fit on $\mathrm{F}^{2}$ & 1.043 \\
\hline Final $R$ indexes $[\mathrm{I}>=2 \sigma(\mathrm{I})]$ & $\mathrm{R}_{1}=0.0368, \mathrm{wR}_{2}=0.0856$ \\
\hline Final $\mathrm{R}$ indexes [all data] & $\mathrm{R}_{1}=0.0526, \mathrm{wR}_{2}=0.0920$ \\
\hline Largest diff. peak/hole / e $\AA^{-3}$ & $1.32 /-2.11$ \\
\hline
\end{tabular}




\section{Structure, crystal data, and refinement for $m-\mathrm{DPOA} \bullet \mathrm{H}_{2} \mathrm{O}$}

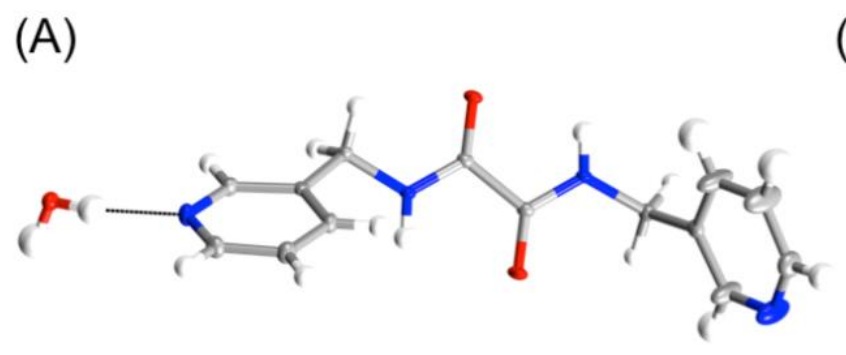

(C)
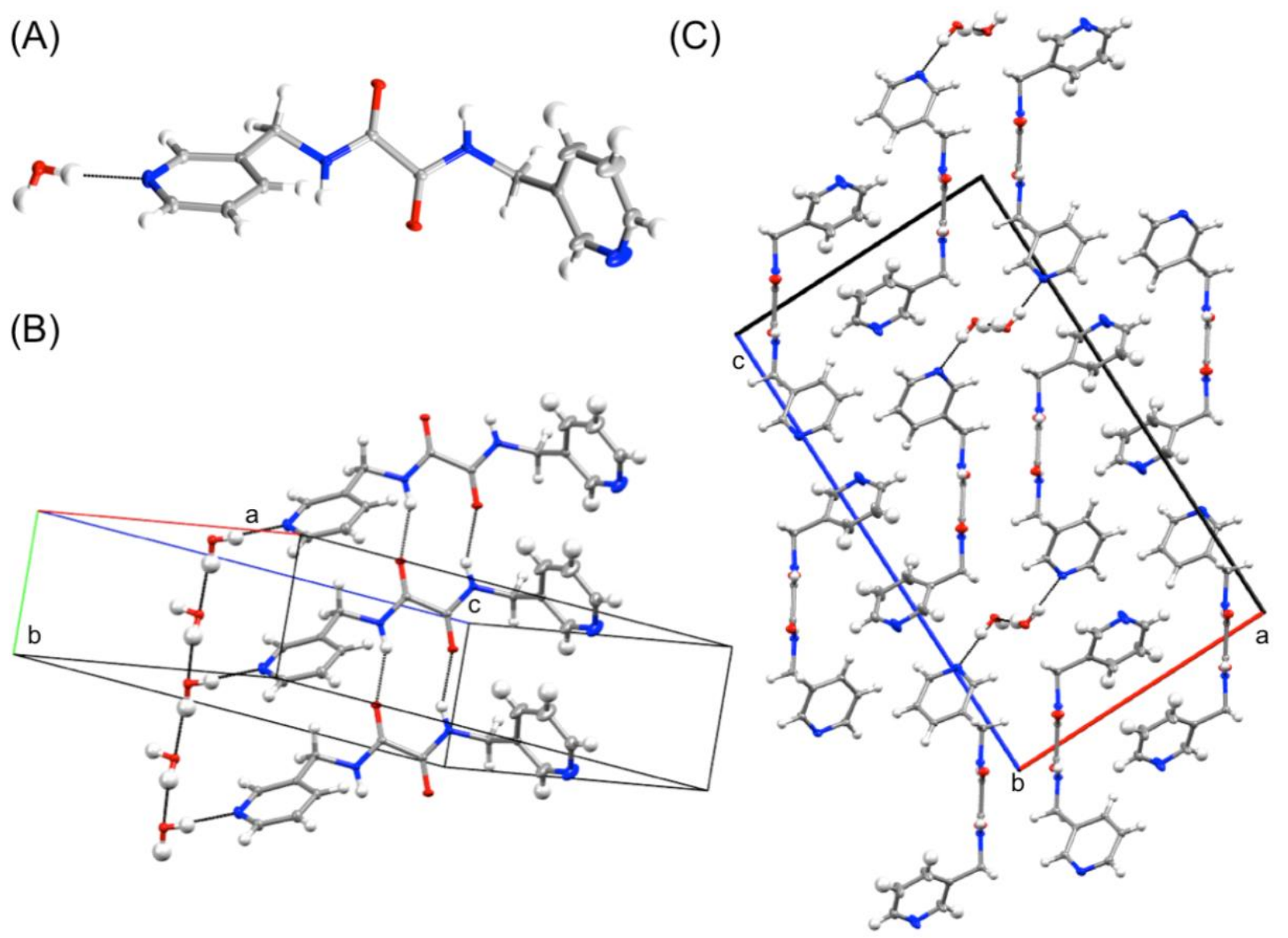

Figure S12. SC-XRD data of $m$-DPOA $\bullet \mathrm{H}_{2} \mathrm{O}$. (A) Single monomer of $m$-DPOA and the O$\mathrm{H} \cdots \mathrm{N}$ HB interactions. (B) Oxalamide HB interactions stack the DPOA molecules down the crystallographic $a$-axis. (C) View down the $b$-axis showing the packing along the $a c$ plane. Two DPOA molecules are through the pyridyl nitrogen connected through HBs with two water molecules.

Refinement details for $\boldsymbol{m}$-DPOA$\cdot \mathrm{H}_{2} \mathrm{O}$ : The compound crystallizes in the monoclinic system. The pattern of systematic absences in the intensity data was consistent with the space group $P 2_{1} / n$, which was verified by structure solution. The asymmetric unit consists of one $\mathrm{C}_{14} \mathrm{H}_{14} \mathrm{~N}_{4} \mathrm{O}_{2}$ molecule and one water molecule. All non-hydrogen atoms were refined with anisotropic displacement parameters. Hydrogen atoms bonded to carbon were located in difference maps before being included as standard riding atoms. Hydrogen atoms bonded to nitrogen, and both water hydrogens, were located and refined freely. The largest residual electron density peak in the final difference map is $0.46 \mathrm{e}^{-} / \AA^{3}$, located $0.75 \AA$ from $\mathrm{C} 1$. 
Table S10. Crystal data and structure refinement for $m-\mathrm{DPOA} \bullet \mathrm{H}_{2} \mathrm{O}$.

\begin{tabular}{|c|c|}
\hline CCDC Identification code & CCDC 1921269 \\
\hline Empirical formula & $\mathrm{C}_{14} \mathrm{H}_{16} \mathrm{~N}_{4} \mathrm{O}_{3}$ \\
\hline Formula weight & 288.31 \\
\hline Temperature/K & $100(2)$ \\
\hline Crystal system & monoclinic \\
\hline Space group & $\mathrm{P} 21_{1} / \mathrm{n}$ \\
\hline $\mathrm{a} / \AA \AA$ & $12.4750(4)$ \\
\hline $\mathrm{b} / \AA$ & $5.0251(2)$ \\
\hline $\mathrm{c} / \AA \AA$ & $22.2327(7)$ \\
\hline$\alpha /^{\circ}$ & 90 \\
\hline$\beta /{ }^{\circ}$ & $90.2380(10)$ \\
\hline$\gamma /{ }^{\circ}$ & 90 \\
\hline Volume $/ \AA^{3}$ & $1393.71(8)$ \\
\hline Z & 4 \\
\hline$\rho_{\text {calc }} \mathrm{g} / \mathrm{cm}^{3}$ & 1.374 \\
\hline$\mu / \mathrm{mm}^{-1}$ & 0.100 \\
\hline$F(000)$ & 608.0 \\
\hline Crystal size $/ \mathrm{mm}^{3}$ & $0.2 \times 0.08 \times 0.04$ \\
\hline Radiation & $\operatorname{MoK} \alpha(\lambda=0.71073)$ \\
\hline $2 \Theta$ range for data collection ${ }^{\circ}$ & 6.384 to 55.498 \\
\hline Index ranges & $-16 \leq \mathrm{h} \leq 16,-6 \leq \mathrm{k} \leq 6,-28 \leq 1 \leq 29$ \\
\hline Reflections collected & 53070 \\
\hline Independent reflections & $3274\left[\mathrm{R}_{\text {int }}=0.0395, \mathrm{R}_{\text {sigma }}=0.0135\right]$ \\
\hline Data/restraints/parameters & $3274 / 0 / 207$ \\
\hline Goodness-of-fit on $\mathrm{F}^{2}$ & 1.044 \\
\hline Final $\mathrm{R}$ indexes $[\mathrm{I}>=2 \sigma(\mathrm{I})]$ & $\mathrm{R}_{1}=0.0378, \mathrm{wR}_{2}=0.0899$ \\
\hline Final $\mathrm{R}$ indexes [all data] & $\mathrm{R}_{1}=0.0447, \mathrm{wR}_{2}=0.0940$ \\
\hline Largest diff. peak/hole / e $\AA^{-3}$ & $0.46 /-0.30$ \\
\hline
\end{tabular}


Structure, crystal data, and refinement for $m$-DPOA $\bullet-T F D I B \bullet(s o l v)_{x}$

(A)

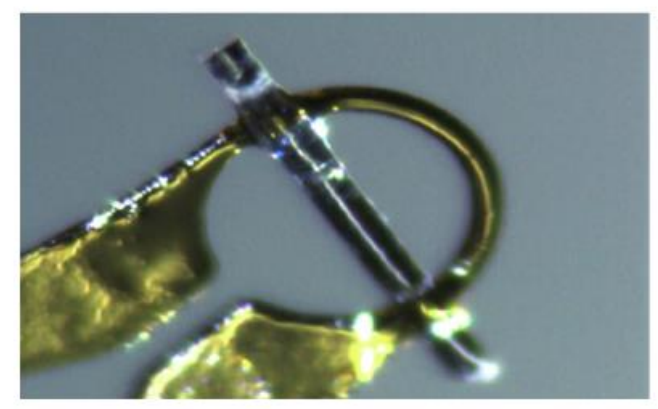

(B

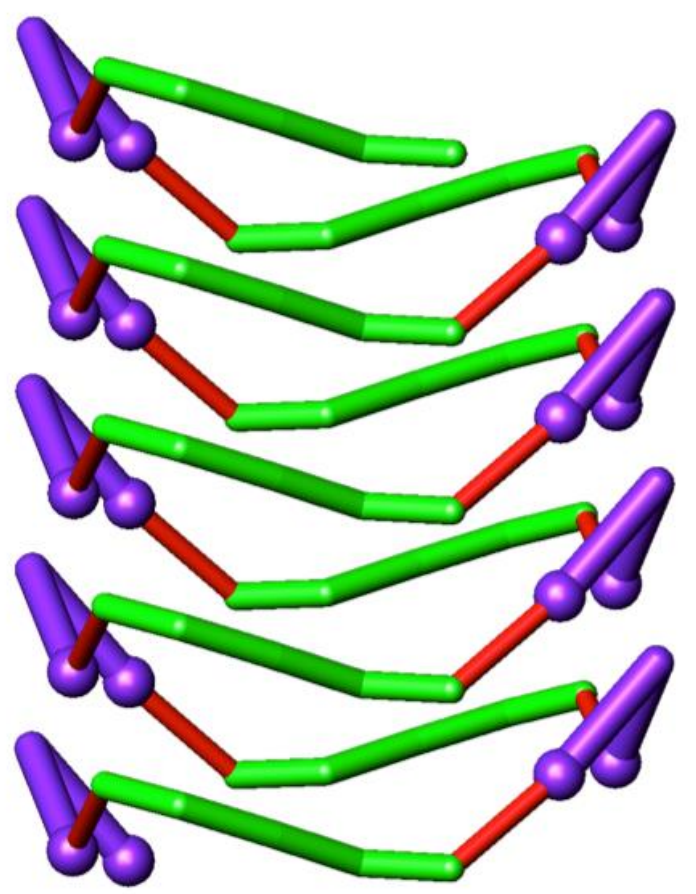

$(\mathrm{C})$

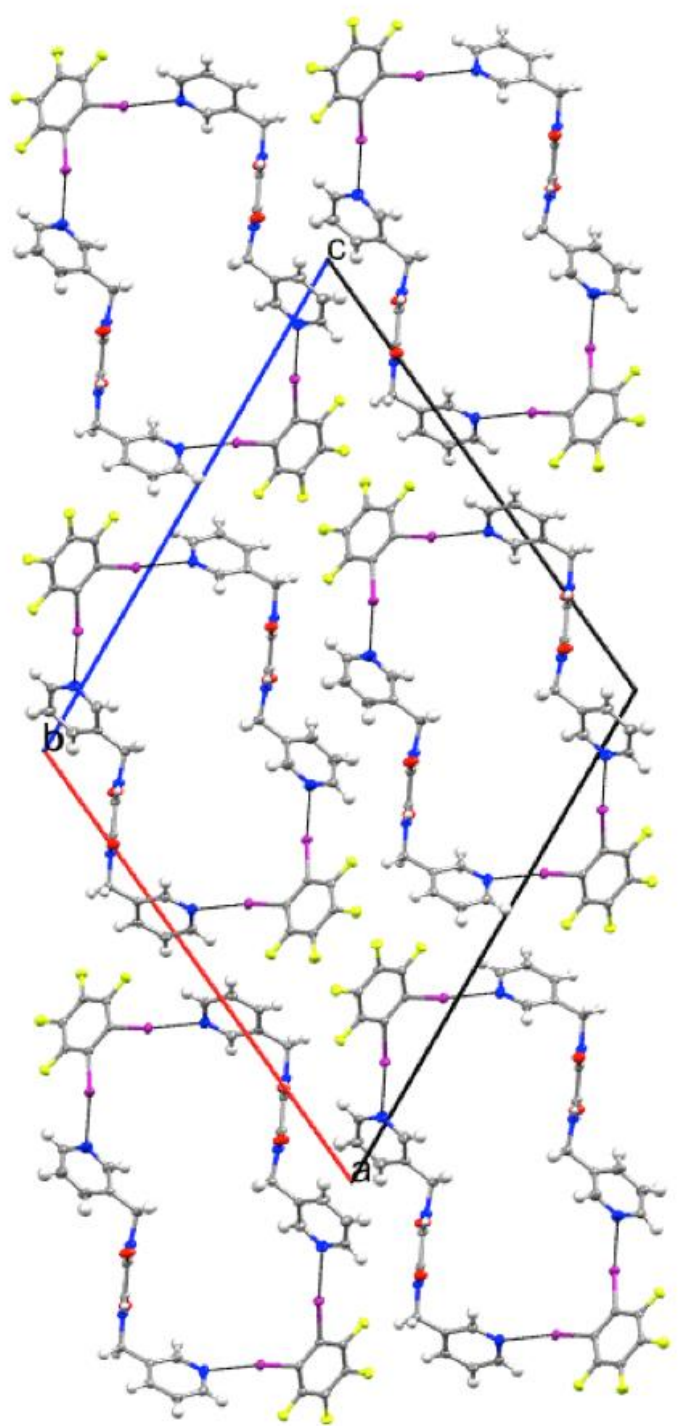

Figure S13. SC-XRD data of $m$-DPOA $\bullet-\mathrm{TFDIB} \bullet($ solv)x. (A) Data crystal. (B) Schematic representation of the infinite spirals formed through self-assembly. (C) View down the $a$-axis showing the oblong tubes formed through $\mathrm{N}-\mathrm{H} \cdots \mathrm{O}$ and $\mathrm{N} \cdots \mathrm{I} \mathrm{HB}$ and $\mathrm{XB}$ interactions. 
Refinement details for $\boldsymbol{m}$-DPOA $\bullet$-TFDIB $\bullet(s o l v)_{\mathbf{x}}$ : The compound crystallizes in the monoclinic system. The pattern of systematic absences in the intensity data was consistent with the space group $P 2_{1} / n$, which was confirmed by structure solution. The asymmetric unit consists of one $\mathrm{C}_{14} \mathrm{H}_{14} \mathrm{~N}_{4} \mathrm{O}_{2}$ molecule, one $o-\mathrm{C}_{6} \mathrm{~F}_{4} \mathrm{I}_{2}$ molecule and a region of disordered solvent molecules. Efforts to model the solvent disorder were unsuccessful. Trial modeling attempts suggest a mixture of species, likely water and the crystallization solvent THF, but also something possessing a heavier atom, possibly dichloromethane. The Squeeze program in PLATON was used to account for these species. ${ }^{5}$ The solvent-accessible volume was calculated to be $593 \AA^{3}$ per unit cell $(22.5 \%$ of the total cell volume), containing the equivalent of 234 electrons per unit cell. The scattering contribution of this electron density was added to the structure factors computed from the known part of the structure during refinement. For comparison, the residual factors were $R 1 / w R 2=$ $0.032 / 0.079$ for the best disorder model, and $R 1 / w R 2=0.025 / 0.049$ after applying Squeeze. The reported crystal density and $F . W$. are calculated from the known part of the structure only. All nonhydrogen atoms were refined with anisotropic displacement parameters. Hydrogen atoms bonded to carbon were located in Fourier difference maps before being placed in geometrically idealized positions and included as riding atoms with $d(\mathrm{C}-\mathrm{H})=0.95 \AA$ and $U$ iso $(\mathrm{H})=1.2 U$ eq $(\mathrm{C})$ for aromatic hydrogen atoms and $d(\mathrm{C}-\mathrm{H})=0.99 \AA$ and $U$ iso $(\mathrm{H})=1.2 U$ eq $(\mathrm{C})$ for methylene hydrogen atoms. Hydrogen atoms bonded to nitrogen were located in difference maps and refined freely. The largest residual electron density peak in the final difference map is $0.56 \mathrm{e}^{-/} \AA^{3}$, located $0.69 \AA$ from $\mathrm{I} 21$. 
Table S11. Crystal data and structure refinement for $m$-DPOA $\bullet o-T F D I B \bullet(s o l v) x$.

\begin{tabular}{|c|c|}
\hline CCDC Identification code & CCDC 1921261 \\
\hline Empirical formula & $\mathrm{C}_{20} \mathrm{H}_{14} \mathrm{~F}_{4} \mathrm{I}_{2} \mathrm{~N}_{4} \mathrm{O}_{2}$ \\
\hline Formula weight & 672.15 \\
\hline Temperature/K & $100(2)$ \\
\hline Crystal system & monoclinic \\
\hline Space group & $\mathrm{P} 21_{1} / \mathrm{n}$ \\
\hline $\mathrm{a} / \AA$ & $23.0893(10)$ \\
\hline $\mathrm{b} / \AA \AA$ & $5.0755(2)$ \\
\hline $\mathrm{c} / \AA$ & $24.7391(11)$ \\
\hline$\alpha /^{\circ}$ & 90 \\
\hline$\beta /{ }^{\circ}$ & $114.4690(10)$ \\
\hline$\gamma /{ }^{\circ}$ & 90 \\
\hline Volume $/ \AA^{3}$ & $2638.78(19)$ \\
\hline $\mathrm{Z}$ & 4 \\
\hline$\rho_{\text {calc }} \mathrm{g} / \mathrm{cm}^{3}$ & 1.692 \\
\hline$\mu / \mathrm{mm}^{-1}$ & 2.433 \\
\hline $\mathrm{F}(000)$ & 1280.0 \\
\hline Crystal size $/ \mathrm{mm}^{3}$ & $0.6 \times 0.08 \times 0.06$ \\
\hline Radiation & $\operatorname{MoK} \alpha(\lambda=0.71073)$ \\
\hline $2 \Theta$ range for data collection $/{ }^{\circ}$ & 4.95 to 60.012 \\
\hline Index ranges & $-32 \leq \mathrm{h} \leq 32,-7 \leq \mathrm{k} \leq 7,-34 \leq 1 \leq 34$ \\
\hline Reflections collected & 93117 \\
\hline Independent reflections & $7667\left[\mathrm{R}_{\mathrm{int}}=0.0526, \mathrm{R}_{\text {sigma }}=0.0281\right]$ \\
\hline Data/restraints/parameters & $7667 / 0 / 298$ \\
\hline Goodness-of-fit on $\mathrm{F}^{2}$ & 1.027 \\
\hline Final $\mathrm{R}$ indexes $[\mathrm{I}>=2 \sigma(\mathrm{I})]$ & $\mathrm{R}_{1}=0.0253, \mathrm{wR}_{2}=0.0463$ \\
\hline Final $\mathrm{R}$ indexes [all data] & $\mathrm{R}_{1}=0.0370, \mathrm{wR}_{2}=0.0488$ \\
\hline Largest diff. peak/hole / e $\AA^{-3}$ & $0.56 /-0.64$ \\
\hline
\end{tabular}




\section{Structure, crystal data, and refinement for $m$-DPOA $m$-TFDIB}

(A)

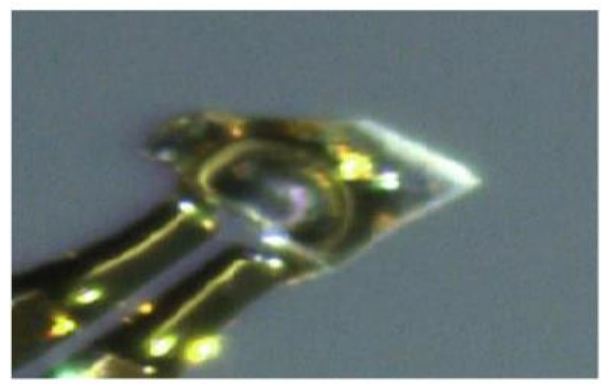

(C)

(B)
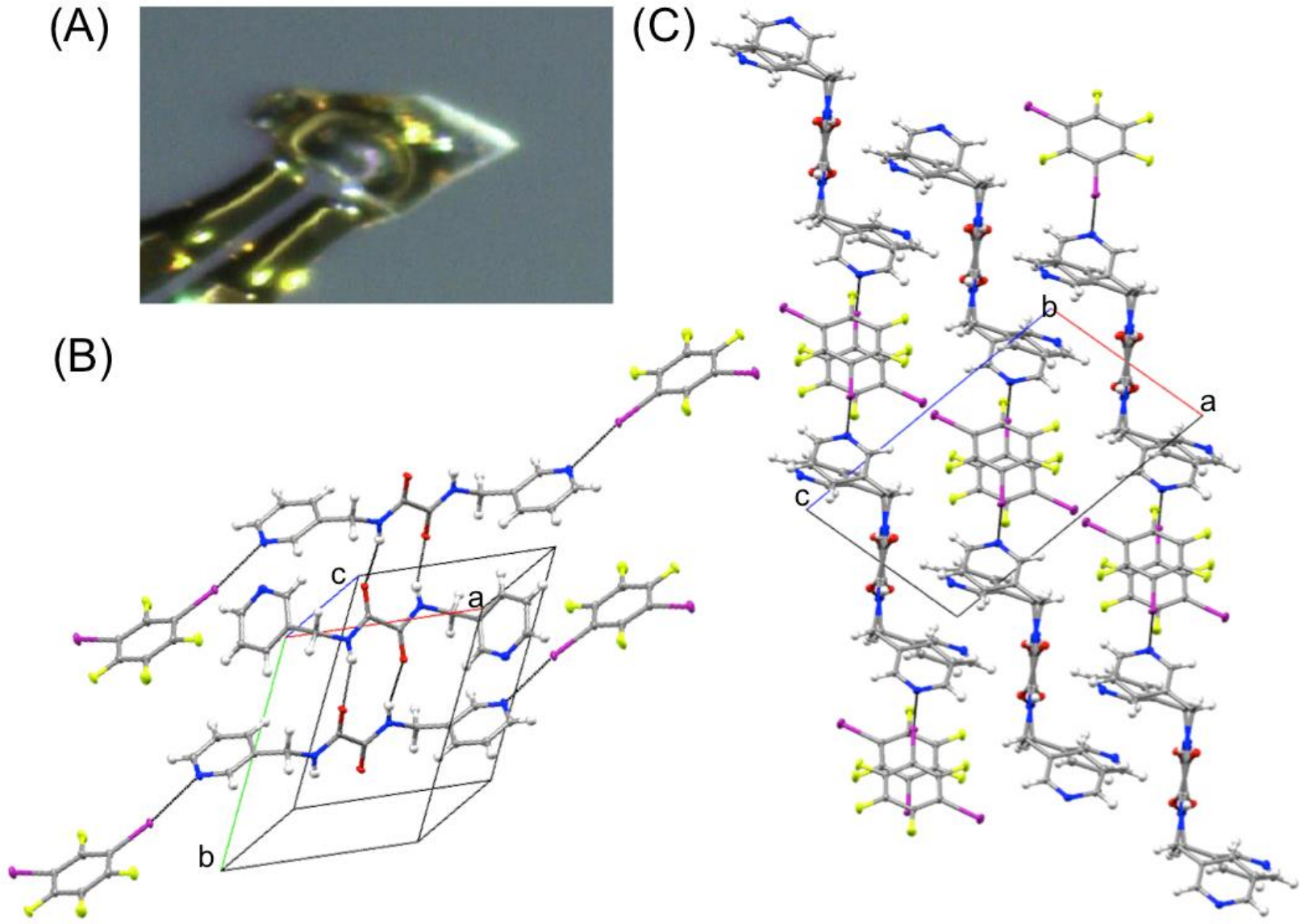

Figure S14. SC-XRD data of $m$-DPOA $m$-TFDIB. (A) Data crystal. (B) $\mathrm{N}-\mathrm{H} \cdots \mathrm{O}$ hydrogen bonding interactions of the oxalamide stack the DPOA molecules down the $b$-axis while the pyridyl nitrogen of every other DPOA molecule is fully satisfied through $\mathrm{N} \cdots \mathrm{I}$ XB interactions .

(C) View down the $b$-axis showing crystal packing.

Refinement details for $\boldsymbol{m}$-DPOA $\boldsymbol{m}$-TFDIB: The compound crystallizes in the triclinic system. The space group P-1 (No. 2) was confirmed by structure solution. The asymmetric unit consists of half each of two independent $\mathrm{C}_{14} \mathrm{H}_{14} \mathrm{~N}_{4} \mathrm{O}_{2}$ molecules located on crystallographic inversion centers and one $\mathrm{C}_{6} \mathrm{~F}_{4} \mathrm{I}_{2}$ molecule. The two half- $\mathrm{C}_{14} \mathrm{H}_{14} \mathrm{~N}_{4} \mathrm{O}_{2}$ molecules were numbered similarly except for label suffixes A or B. All non-hydrogen atoms were refined with anisotropic displacement parameters. Hydrogen atoms bonded to carbon were located in difference Fourier maps before being placed in geometrically idealized positions and included as riding atoms with $\mathrm{d}(\mathrm{C}-\mathrm{H})=0.95 \AA$ and $\mathrm{Uiso}(\mathrm{H})=1.2 \mathrm{Ueq}(\mathrm{C})$ for aromatic hydrogen atoms and $\mathrm{d}(\mathrm{C}-\mathrm{H})=0.99 \AA$ and $\mathrm{Uiso}(\mathrm{H})=1.2 \mathrm{Ueq}(\mathrm{C})$ for methylene hydrogen atoms. The largest residual electron density peak in the final difference map is $0.81 \mathrm{e}-/ \AA^{3}$, located $0.68 \AA$ from $\mathrm{I} 2$. 
Table S12. Crystal data and structure refinement for $m$-DPOA $\bullet m$-TFDIB.

\begin{tabular}{|c|c|}
\hline CCDC Identification code & CCDC 1921262 \\
\hline Empirical formula & $\mathrm{C}_{20} \mathrm{H}_{14} \mathrm{~F}_{4} \mathrm{I}_{2} \mathrm{~N}_{4} \mathrm{O}_{2}$ \\
\hline Formula weight & 672.15 \\
\hline Temperature/K & $100(2)$ \\
\hline Crystal system & triclinic \\
\hline Space group & P-1 \\
\hline $\mathrm{a} / \AA$ & $9.0842(3)$ \\
\hline $\mathrm{b} / \AA$ & $10.0045(3)$ \\
\hline $\mathrm{c} / \AA$ & $13.9193(5)$ \\
\hline$\alpha /^{\circ}$ & $91.966(2)$ \\
\hline$\beta /{ }^{\circ}$ & $103.4420(10)$ \\
\hline$\gamma /{ }^{\circ}$ & $116.3350(10)$ \\
\hline Volume $/ \AA^{3}$ & $1088.89(6)$ \\
\hline $\mathrm{Z}$ & 2 \\
\hline$\rho_{\text {calc }} / \mathrm{cm}^{3}$ & 2.050 \\
\hline$\mu / \mathrm{mm}^{-1}$ & 2.948 \\
\hline $\mathrm{F}(000)$ & 640.0 \\
\hline Crystal size $/ \mathrm{mm}^{3}$ & $0.14 \times 0.12 \times 0.03$ \\
\hline Radiation & $\operatorname{MoK} \alpha(\lambda=0.71073)$ \\
\hline $2 \Theta$ range for data collection ${ }^{\circ}$ & 4.6 to 72.832 \\
\hline Index ranges & $-15 \leq \mathrm{h} \leq 15,-16 \leq \mathrm{k} \leq 16,-23 \leq 1 \leq 23$ \\
\hline Reflections collected & 86167 \\
\hline Independent reflections & $10607\left[\mathrm{R}_{\mathrm{int}}=0.0390, \mathrm{R}_{\text {sigma }}=0.0262\right]$ \\
\hline Data/restraints/parameters & $10607 / 0 / 298$ \\
\hline Goodness-of-fit on $\mathrm{F}^{2}$ & 1.014 \\
\hline Final $\mathrm{R}$ indexes $[\mathrm{I}>=2 \sigma(\mathrm{I})]$ & $\mathrm{R}_{1}=0.0217, \mathrm{wR}_{2}=0.0414$ \\
\hline Final $\mathrm{R}$ indexes [all data] & $\mathrm{R}_{1}=0.0374, \mathrm{wR}_{2}=0.0445$ \\
\hline Largest diff. peak/hole / e $\AA^{-3}$ & $0.81 /-0.83$ \\
\hline
\end{tabular}




\section{Structure, crystal data, and refinement for $m$-DPOA $\bullet(m-\text { TFDIB })_{2} \bullet$ DMSO}

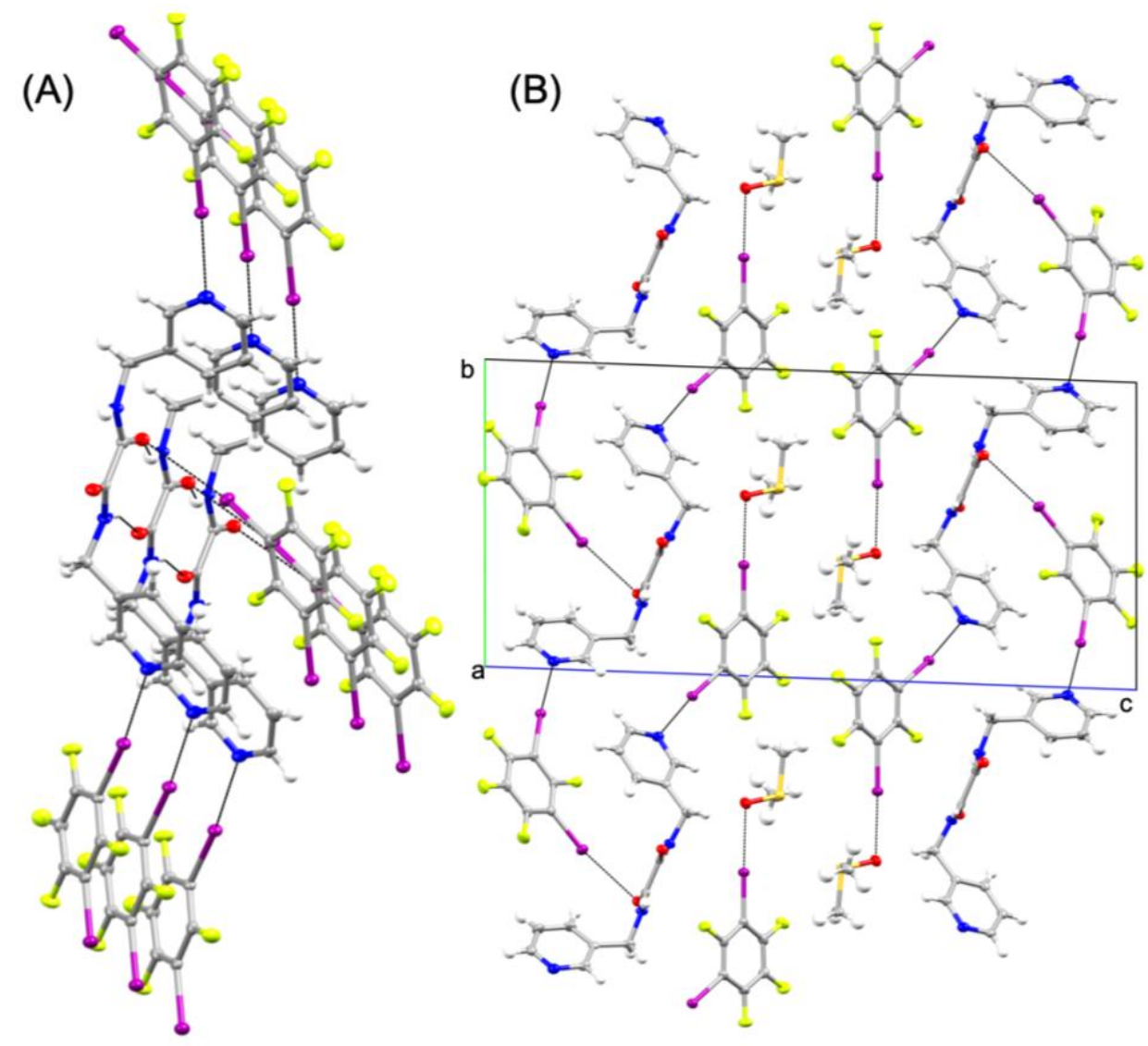

Figure S15. SC-XRD data of $m$-DPOA $\bullet(m \text {-TFDIB })_{2} \bullet$ DMSO. (A) Chains of N-H $\cdots$ O hydrogen bonds drive assembly down the crystallographic $a$-axis while the TFDIB molecules participate in $\mathrm{O} \cdots \mathrm{I}$ and $\mathrm{N} \cdots \mathrm{I}$ XB interactions. (B) View down the $a$-axis showing the crystal packing and DMSO molecules within the lattice.

Refinement details for $\boldsymbol{m}$-DPOA $\bullet(\boldsymbol{m} \text {-TFDIB })_{2} \bullet$ DMSO: The compound crystallizes in the triclinic system. The space group P-1 (No. 2) was confirmed by structure solution. The asymmetric unit consists of one $m-\mathrm{C}_{14} \mathrm{H}_{14} \mathrm{~N}_{4} \mathrm{O}_{2}$ molecule, two crystallographically independent $m$ $\mathrm{C}_{6} \mathrm{~F}_{4} \mathrm{I}_{2}$ molecules and one DMSO molecule. The DMSO molecule is disordered over two closely separated positions with a major occupancy (component A) of $0.59(1)$. The minor component (B) was restrained to be similar to the major using a SHELX SAME instruction. The anisotropic displacement parameters of nearly superimposed atoms were held equal. All non-hydrogen atoms were refined with anisotropic displacement parameters. Hydrogen atoms bonded to carbon were located in Fourier difference maps before being placed in geometrically idealized positions and included as riding atoms with $\mathrm{d}(\mathrm{C}-\mathrm{H})=0.95 \AA$ and $\mathrm{Uiso}(\mathrm{H})=1.2 \mathrm{Ueq}(\mathrm{C})$ for aromatic hydrogen atoms, $\mathrm{d}(\mathrm{C}-\mathrm{H})=0.99 \AA$ and $\mathrm{Uiso}(\mathrm{H})=1.2 \mathrm{Ueq}(\mathrm{C})$ for methylene hydrogens and $\mathrm{d}(\mathrm{C}-\mathrm{H})=0.98 \AA$ and $\operatorname{Uiso}(\mathrm{H})=1.5 \mathrm{Ueq}(\mathrm{C})$ for methyl hydrogens. The methyl hydrogens were allowed to rotate as a rigid group to the orientation of maximum observed electron density. The two urea hydrogen atoms were located in difference maps and refined freely. The largest residual electron density peak in the final difference map is $0.84 \mathrm{e}-/ \AA^{3}$, located $1.10 \AA$ from F33. 
Table S13. Crystal data and structure refinement for $m$-DPOA $\bullet(m \text {-TFDIB })_{2} \bullet$ DMSO.

CCDC Identification code

Empirical formula

Formula weight

Temperature/K

Crystal system

Space group

$\mathrm{a} / \AA$

$\mathrm{b} / \AA$

$\mathrm{c} / \AA$

$\alpha /{ }^{\circ}$

$\beta /{ }^{\circ}$

$\gamma / 0$

Volume $/ \AA^{3}$

Z

$\rho_{\text {calc }} / \mathrm{cm}^{3}$

$\mu / \mathrm{mm}^{-1}$

$\mathrm{F}(000)$

Crystal size $/ \mathrm{mm}^{3}$

Radiation

$2 \Theta$ range for data collection $/{ }^{\circ}$

Index ranges

Reflections collected

Independent reflections

Data/restraints/parameters

Goodness-of-fit on $\mathrm{F}^{2}$

Final $\mathrm{R}$ indexes $[\mathrm{I}>=2 \sigma(\mathrm{I})]$

Final R indexes [all data]

Largest diff. peak/hole / e $\AA^{-3}$
CCDC 1921263

$\mathrm{C}_{28} \mathrm{H}_{20} \mathrm{~F}_{8} \mathrm{I}_{4} \mathrm{~N}_{4} \mathrm{O}_{3} \mathrm{~S}$

1152.14

100(2)

triclinic

P-1

$5.0099(3)$

$12.8325(6)$

26.8563(13)

91.6860(10)

$92.005(2)$

99.5590(10)

$1700.48(15)$

2

2.250

3.808

1080.0

$0.34 \times 0.04 \times 0.02$

$\operatorname{MoK} \alpha(\lambda=0.71073)$

4.348 to 55.398

$-6 \leq \mathrm{h} \leq 6,-16 \leq \mathrm{k} \leq 16,-35 \leq 1 \leq 35$

50652

$7962\left[\mathrm{R}_{\text {int }}=0.0576, \mathrm{R}_{\text {sigma }}=0.0488\right]$

$7962 / 8 / 465$

1.044

$\mathrm{R}_{1}=0.0355, \mathrm{wR}_{2}=0.0513$

$\mathrm{R}_{1}=0.0624, \mathrm{wR}_{2}=0.0567$

$0.84 /-0.95$ 


\section{Structure, crystal data, and refinement for $m$-DPOA $\bullet$-TFDIB}
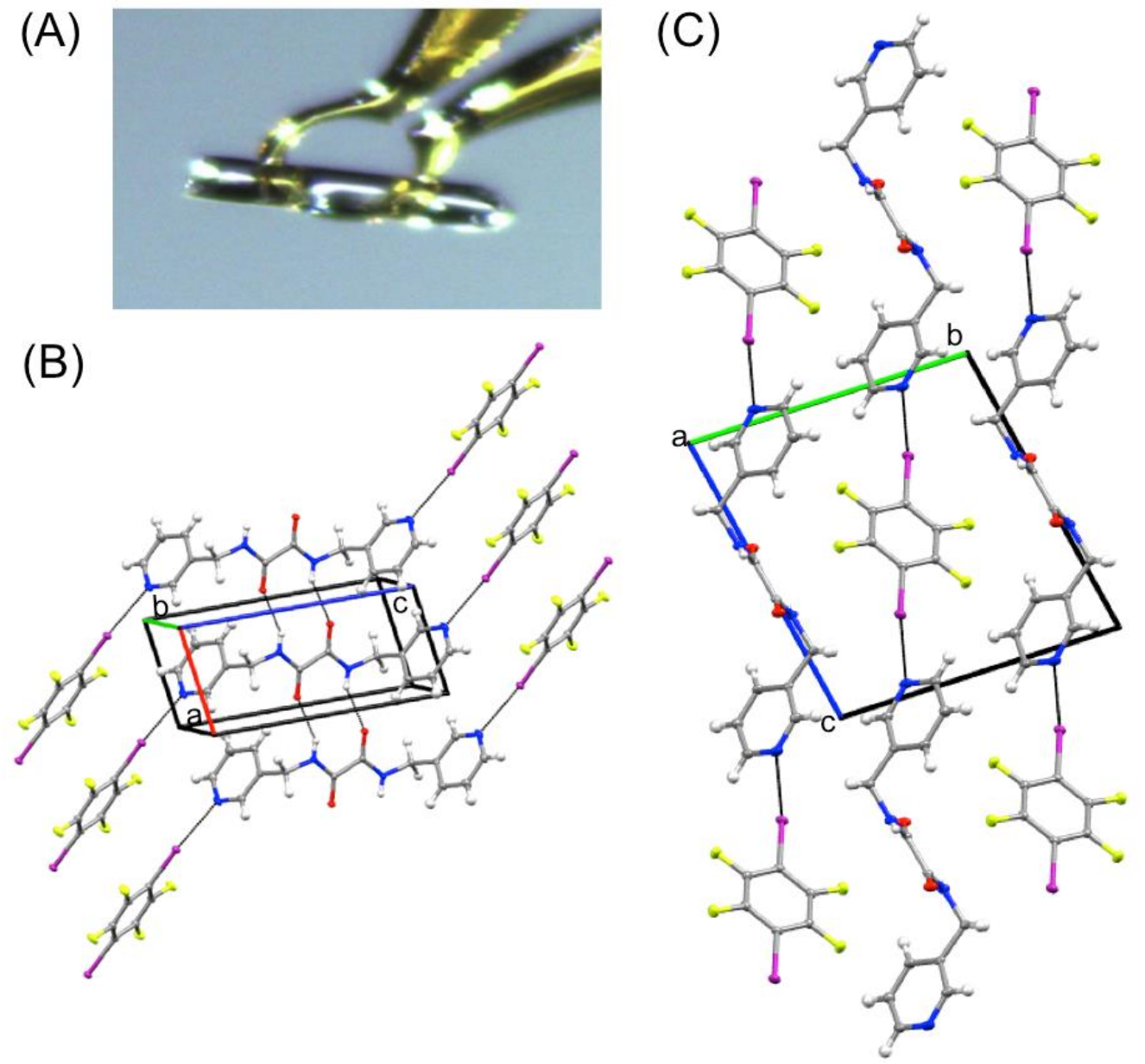

Figure S16. SC-XRD data of $m$-DPOA $\bullet$-TFDIB (A) Data crystal. (B) Infinite chains of N $\cdots$ I $\mathrm{XB}$ and $\mathrm{N}-\mathrm{H} \cdots \mathrm{O}$ HB interactions drive assembly down the $a$ - and $c$-axis. (C) View down the $a$-axis showing the infinite $\mathrm{XB}$ chains.

Refinement details for $\boldsymbol{m}$-DPOA $\boldsymbol{p}$-TFDIB: The compound crystallizes in the triclinic system. The space group P-1 (No. 2) was confirmed by structure solution. The asymmetric unit consists of half each of one $\mathrm{C}_{14} \mathrm{H}_{14} \mathrm{~N}_{4} \mathrm{O}_{2}$ and one $\mathrm{C}_{6} \mathrm{~F}_{4} \mathrm{I}_{2}$ molecule, both of which are located on crystallographic inversion centers. All non-hydrogen atoms were refined with anisotropic displacement parameters. Hydrogen atoms bonded to carbon were located in Fourier difference maps before being placed in geometrically idealized positions and included as riding atoms with $\mathrm{d}(\mathrm{C}-\mathrm{H})=0.95 \AA$ and $\mathrm{Uiso}(\mathrm{H})=1.2 \mathrm{Ueq}(\mathrm{C})$ for aromatic hydrogen atoms and $\mathrm{d}(\mathrm{C}-\mathrm{H})=0.99 \AA$ and $\operatorname{Uiso}(\mathrm{H})=1.2 \mathrm{Ueq}(\mathrm{C})$ for methylene hydrogens. The largest residual electron density peak in the final difference map is $0.57 \mathrm{e}-/ \AA^{3}$, located $0.77 \AA$ from $\mathrm{C} 1$. 
Table S14. Crystal data and structure refinement for $m$-DPOA $\bullet p$-TFDIB.

CCDC Identification code

Empirical formula

Formula weight

Temperature/K

Crystal system

Space group

$\mathrm{a} / \AA$

$\mathrm{b} / \AA$

$\mathrm{c} / \AA$

$\alpha /{ }^{\circ}$

$\beta /{ }^{\circ}$

$\gamma /{ }^{\circ}$

Volume $/ \AA^{3}$

Z

$\rho_{\text {calc }} \mathrm{g} / \mathrm{cm}^{3}$

$\mu / \mathrm{mm}^{-1}$

$\mathrm{F}(000)$

Crystal size $/ \mathrm{mm}^{3}$

Radiation

$2 \Theta$ range for data collection ${ }^{\circ}$

Index ranges

Reflections collected

Independent reflections

Data/restraints/parameters

Goodness-of-fit on $\mathrm{F}^{2}$

Final $\mathrm{R}$ indexes $[\mathrm{I}>=2 \sigma(\mathrm{I})]$

Final R indexes [all data]

Largest diff. peak/hole / e $\AA^{-3}$
CCDC 1921264

$\mathrm{C}_{20} \mathrm{H}_{14} \mathrm{~F}_{4} \mathrm{I}_{2} \mathrm{~N}_{4} \mathrm{O}_{2}$

672.15

100(2)

triclinic

P-1

5.0220(2)

10.1929(4)

$11.0684(4)$

$78.0680(10)$

$79.1010(10)$

$83.7640(10)$

542.91(4)

1

2.056

2.956

320.0

$0.36 \times 0.08 \times 0.06$

$\operatorname{MoK} \alpha(\lambda=0.71073)$

5.038 to 60.26

$-7 \leq \mathrm{h} \leq 7,-14 \leq \mathrm{k} \leq 14,-15 \leq 1 \leq 15$

29358

$3200\left[\mathrm{R}_{\mathrm{int}}=0.0243, \mathrm{R}_{\text {sigma }}=0.0144\right]$

$3200 / 0 / 150$

1.089

$\mathrm{R}_{1}=0.0150, \mathrm{wR}_{2}=0.0315$

$\mathrm{R}_{1}=0.0173, \mathrm{wR}_{2}=0.0322$

$0.57 /-0.36$ 


\section{Structure, crystal data, and refinement for $p$-DPOA}
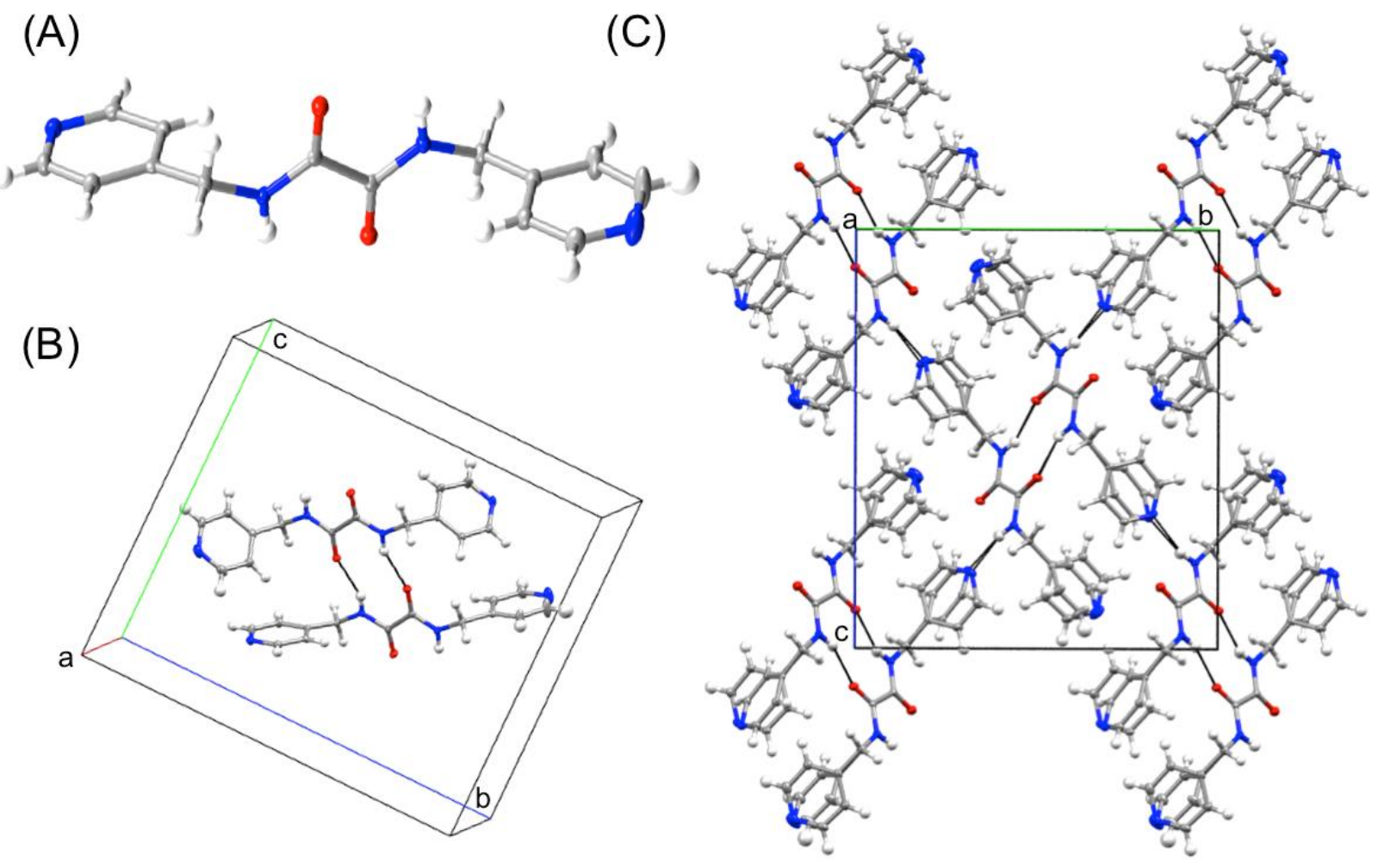

Figure S17. SC-XRD data of $p$-DPOA. (A) Single monomer unit of $p$-DPOA. (B) The $p$-DPOA ligands are organized as dimers through $\mathrm{N}-\mathrm{H} \cdots \mathrm{O}$ and $\mathrm{N}-\mathrm{H} \cdots \mathrm{N}$ interaction. (C) View down the $a$-axis showing the herringbone pattern of $p$-DPOA dimers along the $b c$ plane.

Refinement details for $\boldsymbol{p}$-DPOA: The compound crystallizes in the monoclinic system. The pattern of systematic absences in the intensity data was consistent with the space group P21/n, which was confirmed by structure solution. The asymmetric unit consists of two crystallographically independent but chemically identical molecules. All non-hydrogen atoms were refined with anisotropic displacement parameters. Hydrogen atoms bonded to carbon were located in Fourier difference maps before being placed in geometrically idealized positions and included as riding atoms with $\mathrm{d}(\mathrm{C}-\mathrm{H})=0.95 \AA$ and $\mathrm{Uiso}(\mathrm{H})=1.2 \mathrm{Ueq}(\mathrm{C})$ for pyridyl hydrogen atoms and $\mathrm{d}(\mathrm{C}-\mathrm{H})=0.99 \AA$ and $\mathrm{Uiso}(\mathrm{H})=1.2 \mathrm{Ueq}(\mathrm{C})$ for methylene hydrogens. Hydrogen atoms bonded to nitrogen were located in difference maps and refined freely. The largest residual electron density peak in the final difference map is $0.33 \mathrm{e}-/ \AA^{3}$, located $0.74 \AA$ from $\mathrm{C} 10 \mathrm{~B}$. 
Table S15. Crystal data and structure refinement for $p$-DPOA.

\begin{tabular}{|c|c|}
\hline Empirical formula & $\mathrm{C}_{14} \mathrm{H}_{14} \mathrm{~N}_{4} \mathrm{O}_{2}$ \\
\hline Formula weight & 270.29 \\
\hline Temperature/K & $100(2)$ \\
\hline Crystal system & monoclinic \\
\hline Space group & $\mathrm{P} 21 / \mathrm{n}$ \\
\hline $\mathrm{a} / \AA$ & $9.4810(10)$ \\
\hline $\mathrm{b} / \AA$ & $15.4415(16)$ \\
\hline $\mathrm{c} / \AA$ & $17.8475(19)$ \\
\hline$\alpha /^{\circ}$ & 90 \\
\hline$\beta /{ }^{\circ}$ & $93.803(3)$ \\
\hline$\gamma /{ }^{\circ}$ & 90 \\
\hline Volume $/ \AA^{3}$ & $2607.1(5)$ \\
\hline $\mathrm{Z}$ & 8 \\
\hline$\rho_{\text {calc }} \mathrm{g} / \mathrm{cm}^{3}$ & 1.377 \\
\hline$\mu / \mathrm{mm}^{-1}$ & 0.096 \\
\hline $\mathrm{F}(000)$ & 1136.0 \\
\hline Crystal size $/ \mathrm{mm}^{3}$ & $0.44 \times 0.16 \times 0.03$ \\
\hline Radiation & $\operatorname{MoK} \alpha(\lambda=0.71073)$ \\
\hline $2 \Theta$ range for data collection ${ }^{\circ}$ & 4.574 to 55.672 \\
\hline Index ranges & $-12 \leq \mathrm{h} \leq 12,-20 \leq \mathrm{k} \leq 20,-23 \leq 1 \leq 23$ \\
\hline Reflections collected & 93373 \\
\hline Independent reflections & $6142\left[\mathrm{R}_{\mathrm{int}}=0.0878, \mathrm{R}_{\text {sigma }}=0.0522\right]$ \\
\hline Data/restraints/parameters & $6142 / 0 / 378$ \\
\hline Goodness-of-fit on $\mathrm{F}^{2}$ & 1.010 \\
\hline Final $R$ indexes $[\mathrm{I}>=2 \sigma(\mathrm{I})]$ & $\mathrm{R}_{1}=0.0436, \mathrm{wR}_{2}=0.0900$ \\
\hline Final $\mathrm{R}$ indexes [all data] & $\mathrm{R}_{1}=0.0941, \mathrm{wR}_{2}=0.1059$ \\
\hline Largest diff. peak/hole / e $\AA^{-3}$ & $0.33 /-0.20$ \\
\hline
\end{tabular}




\section{Structure, crystal data, and refinement for $p$-DPOA $\bullet$-TFDIB}

(A)

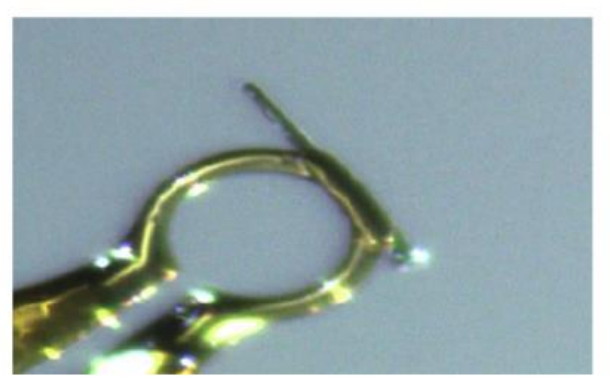

(B)

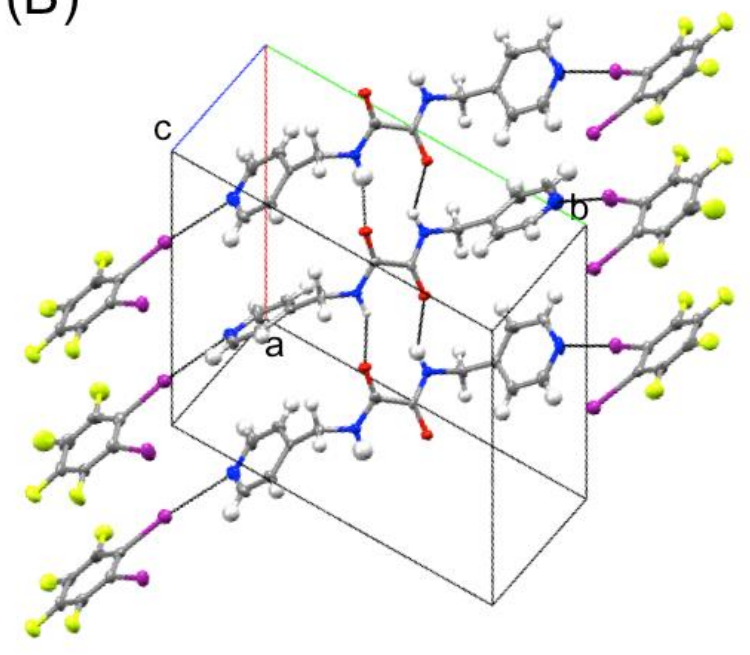

(C)

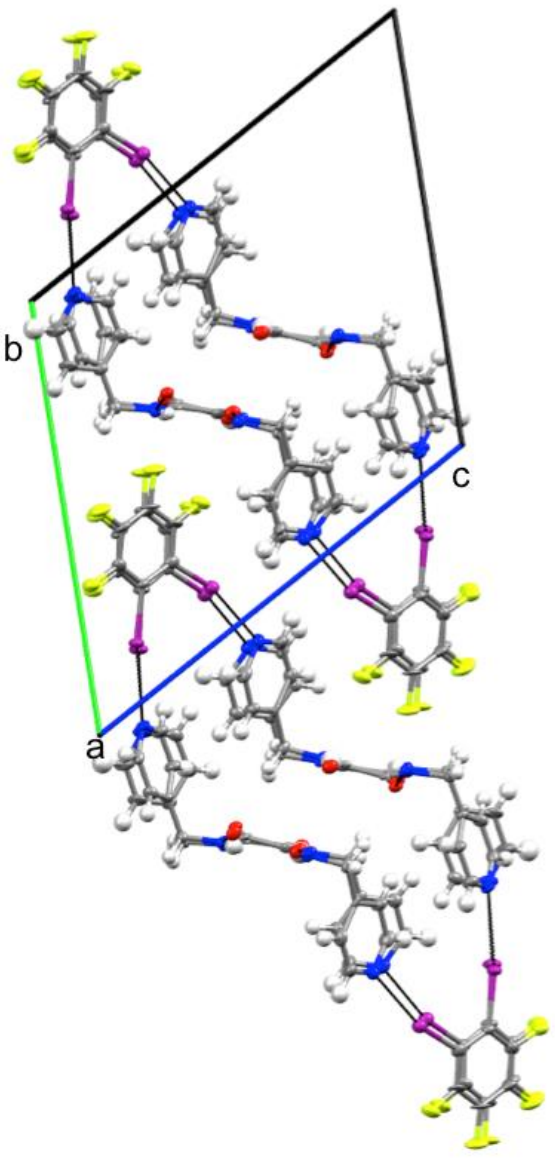

Figure S18. SC-XRD data of $p$-DPOA $\bullet$-TFDIB. (A) Data crystal. (B) DPOA molecules are stacked through chains of hydrogen bonds along the crystallographic $a$-axis with fully complementary $\mathrm{N} \cdots \mathrm{I}$ XB interactions. (C) View down the $a$-axis showing the packing of the "chair" shaped macrocycles along the $b c$ plane.

Refinement details for $\boldsymbol{p}$-DPOA $\bullet$-TFDIB: The compound crystallizes in the triclinic system. The space group P-1 (No. 2) was confirmed by structure solution. The asymmetric unit consists of two independent $p-\mathrm{C}_{14} \mathrm{H}_{14} \mathrm{~N}_{4} \mathrm{O}_{2}$ molecules and two independent $o-\mathrm{C}_{6} \mathrm{~F}_{4} \mathrm{I}_{2}$ molecules. All non-hydrogen atoms were refined with anisotropic displacement parameters. Hydrogen atoms bonded to carbon were located in Fourier difference maps before being placed in geometrically idealized positions and included as riding atoms with $\mathrm{d}(\mathrm{C}-\mathrm{H})=0.95 \AA$ and $\mathrm{Uiso}(\mathrm{H})=1.2 \mathrm{Ueq}(\mathrm{C})$ for aromatic hydrogen atoms and $\mathrm{d}(\mathrm{C}-\mathrm{H})=0.99 \AA$ and $\mathrm{Uiso}(\mathrm{H})=1.2 \mathrm{Ueq}(\mathrm{C})$ for methylene hydrogen atoms. Hydrogen atoms bonded to nitrogen were located in difference Fourier maps and refined isotropically with their N-H distances restrained to be similar (SHELX SADI). The largest residual electron density peak in the final difference map is $1.00 \mathrm{e}-/ \AA^{3}$, located $0.75 \AA$ from I $2 \mathrm{~A}$. 
Table S16. Crystal data and structure refinement for $p$-DPOA $\bullet$-TFDIB.

\begin{tabular}{|c|c|}
\hline CCDC Identification code & CCDC 1921265 \\
\hline Empirical formula & $\mathrm{C}_{20} \mathrm{H}_{14} \mathrm{~F}_{4} \mathrm{I}_{2} \mathrm{~N}_{4} \mathrm{O}_{2}$ \\
\hline Formula weight & 672.15 \\
\hline Temperature/K & $100(2)$ \\
\hline Crystal system & triclinic \\
\hline Space group & $\mathrm{P}-1$ \\
\hline $\mathrm{a} / \AA$ & $9.9875(6)$ \\
\hline $\mathrm{b} / \AA$ & $16.1222(10)$ \\
\hline $\mathrm{c} / \AA \AA$ & $16.3270(11)$ \\
\hline$\alpha /^{\circ}$ & $60.563(2)$ \\
\hline$\beta /{ }^{\circ}$ & $86.126(2)$ \\
\hline$\gamma /{ }^{\circ}$ & $72.709(2)$ \\
\hline Volume $/ \AA^{3}$ & $2176.3(2)$ \\
\hline Z & 4 \\
\hline$\rho_{\text {calc }} \mathrm{g} / \mathrm{cm}^{3}$ & 2.051 \\
\hline$\mu / \mathrm{mm}^{-1}$ & 2.950 \\
\hline $\mathrm{F}(000)$ & 1280.0 \\
\hline Crystal size $/ \mathrm{mm}^{3}$ & $0.16 \times 0.04 \times 0.02$ \\
\hline Radiation & $\operatorname{MoK} \alpha(\lambda=0.71073)$ \\
\hline $2 \Theta$ range for data collection $/^{\circ}$ & 4.29 to 50.048 \\
\hline Index ranges & $-11 \leq \mathrm{h} \leq 11,-18 \leq \mathrm{k} \leq 19,-19 \leq 1 \leq 19$ \\
\hline Reflections collected & 40245 \\
\hline Independent reflections & $7694\left[\mathrm{R}_{\text {int }}=0.0991, \mathrm{R}_{\text {sigma }}=0.0907\right]$ \\
\hline Data/restraints/parameters & $7694 / 6 / 594$ \\
\hline Goodness-of-fit on $\mathrm{F}^{2}$ & 1.012 \\
\hline Final $R$ indexes $[I>=2 \sigma(I)]$ & $\mathrm{R}_{1}=0.0501, \mathrm{wR}_{2}=0.0804$ \\
\hline Final $\mathrm{R}$ indexes [all data] & $\mathrm{R}_{1}=0.1097, \mathrm{wR}_{2}=0.0964$ \\
\hline Largest diff. peak/hole / e $\AA^{-3}$ & $1.00 /-1.08$ \\
\hline Largest diff. peak/hole / e $\AA^{-3}$ & $0.33 /-0.20$ \\
\hline
\end{tabular}




\section{Structure, crystal data, and refinement for $p$-DPOA $\bullet m$-TFDIB}

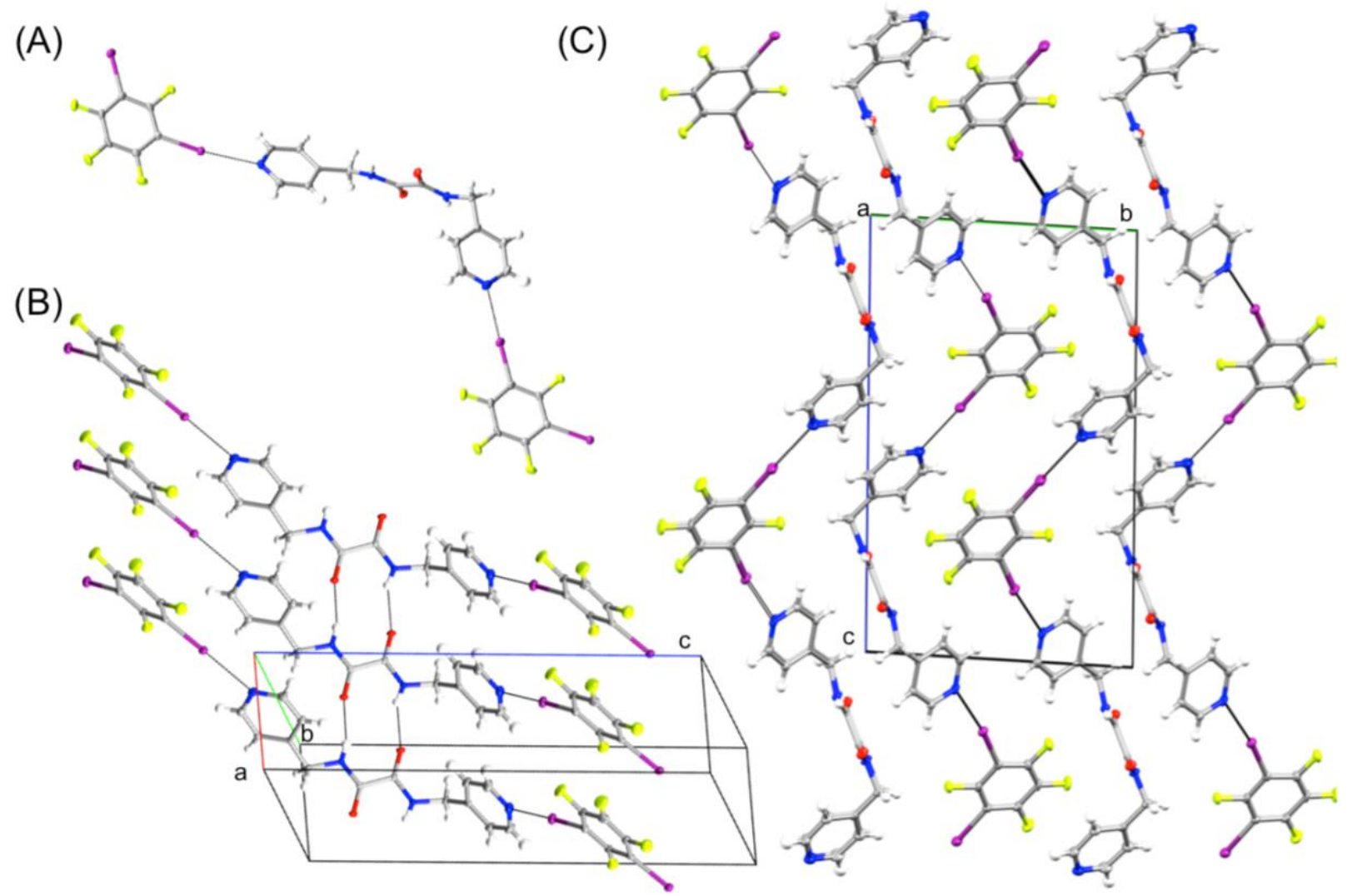

Figure S19. SC-XRD data of $p$-DPOA $m$-TFDIB. (A) N $\cdots$ I XB interactions (B) DPOA molecules are stacked through chains of hydrogen bonds along the crystallographic $a$-axis with fully complementary $\mathrm{N} \cdots \mathrm{I}$ XB interactions. (C) View down the $a$-axis showing the infinite chains of $\mathrm{HB}$ and $\mathrm{XB}$ interactions.

Refinement details for $\boldsymbol{p}$-DPOA $\boldsymbol{m}$-TFDIB: The compound crystallizes in the triclinic system. The space group P-1 (No. 2) was confirmed by structure solution. The asymmetric unit consists of one $p-\mathrm{C}_{14} \mathrm{H}_{14} \mathrm{~N}_{4} \mathrm{O}_{2}$ molecule and one $m-\mathrm{C}_{6} \mathrm{~F}_{4} \mathrm{I}_{2}$ molecule. All non-hydrogen atoms were refined with anisotropic displacement parameters. Hydrogen atoms bonded to carbon were located in Fourier difference maps before being placed in geometrically idealized positions and included as riding atoms with $\mathrm{d}(\mathrm{C}-\mathrm{H})=0.95 \AA$ and $\operatorname{Uiso}(\mathrm{H})=1.2 \mathrm{Ueq}(\mathrm{C})$ for aromatic hydrogen atoms and $\mathrm{d}(\mathrm{C}-\mathrm{H})=0.99 \AA$ and $\operatorname{Uiso}(\mathrm{H})=1.2 \mathrm{Ueq}(\mathrm{C})$ for methylene hydrogens. The two unique hydrogen atoms bonded to nitrogen were located in Fourier difference maps and refined freely. The largest residual electron density peak in the final difference map is $0.69 \mathrm{e}-/ \AA^{3}$, located $1.52 \AA$ from N4. 
Table S17. Crystal data and structure refinement for $p$-DPOA $\bullet m$-TFDIB.

\begin{tabular}{|c|c|}
\hline CCDC Identification code & CCDC 1921266 \\
\hline Empirical formula & $\mathrm{C}_{20} \mathrm{H}_{14} \mathrm{~F}_{4} \mathrm{I}_{2} \mathrm{~N}_{4} \mathrm{O}_{2}$ \\
\hline Formula weight & 672.15 \\
\hline Temperature/K & $100(2)$ \\
\hline Crystal system & triclinic \\
\hline Space group & $\mathrm{P}-1$ \\
\hline $\mathrm{a} / \AA$ & $5.0379(4)$ \\
\hline $\mathrm{b} / \AA$ & $11.7100(8)$ \\
\hline $\mathrm{c} / \AA ̊$ & $19.0014(13)$ \\
\hline$\alpha{ }^{\circ}$ & $86.095(2)$ \\
\hline$\beta /{ }^{\circ}$ & $84.019(2)$ \\
\hline$\gamma /{ }^{\circ}$ & $79.937(2)$ \\
\hline Volume $/ \AA^{3}$ & $1096.29(14)$ \\
\hline $\mathrm{Z}$ & 2 \\
\hline$\rho_{\text {calc }} \mathrm{g} / \mathrm{cm}^{3}$ & 2.036 \\
\hline$\mu / \mathrm{mm}^{-1}$ & 2.928 \\
\hline $\mathrm{F}(000)$ & 640.0 \\
\hline Crystal size $/ \mathrm{mm}^{3}$ & $0.24 \times 0.02 \times 0.02$ \\
\hline Radiation & $\operatorname{MoK} \alpha(\lambda=0.71073)$ \\
\hline $2 \Theta$ range for data collection $/{ }^{\circ}$ & 4.316 to 56.702 \\
\hline Index ranges & $-6 \leq \mathrm{h} \leq 6,-15 \leq \mathrm{k} \leq 15,-25 \leq 1 \leq 25$ \\
\hline Reflections collected & 36916 \\
\hline Independent reflections & $5459\left[\mathrm{R}_{\mathrm{int}}=0.0506, \mathrm{R}_{\text {sigma }}=0.0428\right]$ \\
\hline Data/restraints/parameters & $5459 / 0 / 298$ \\
\hline Goodness-of-fit on $\mathrm{F}^{2}$ & 1.020 \\
\hline Final $R$ indexes $[I>=2 \sigma(I)]$ & $\mathrm{R}_{1}=0.0296, \mathrm{wR}_{2}=0.0394$ \\
\hline Final $\mathrm{R}$ indexes [all data] & $\mathrm{R}_{1}=0.0539, \mathrm{wR}_{2}=0.0438$ \\
\hline Largest diff. peak/hole / e $\AA^{-3}$ & $0.69 /-0.56$ \\
\hline Largest diff. peak/hole / e $\AA^{-3}$ & $0.33 /-0.20$ \\
\hline
\end{tabular}




\section{Structure, crystal data, and refinement for $p$-DPOA $\bullet(m-\text { TFDIB })_{2}$}

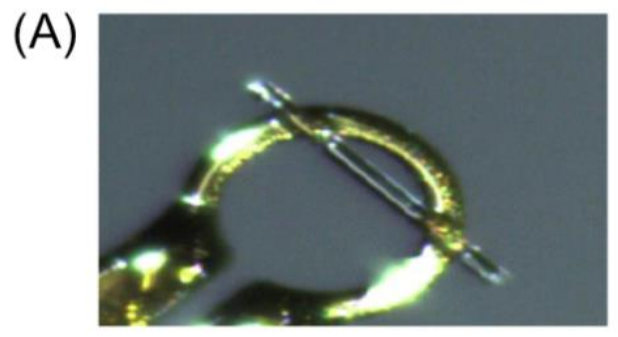

(B)

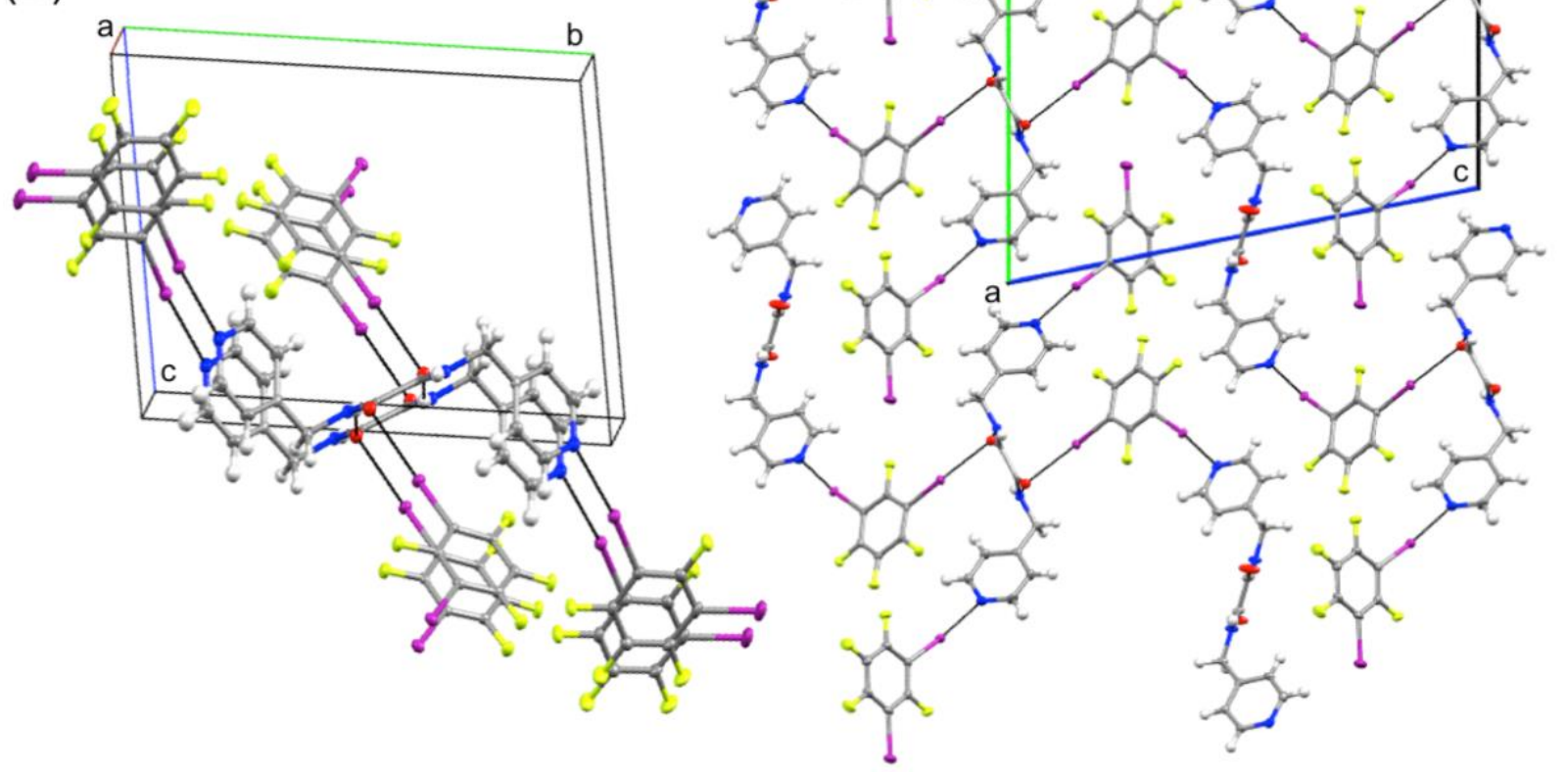

(C)
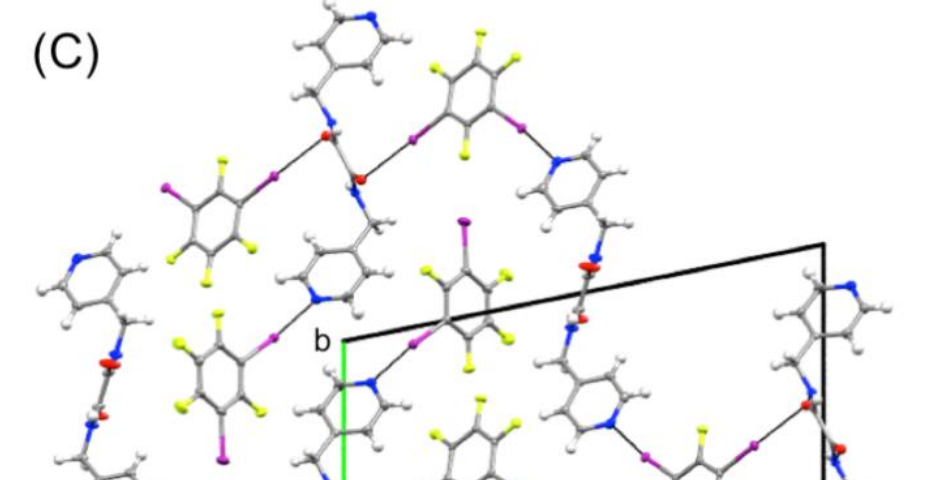

Figure S20. SC-XRD data of $p$-DPOA $\bullet(m \text {-TFDIB })_{2}$. (A) Data crystal. (B) Chains of $\mathrm{N}-\mathrm{H} \cdots \mathrm{O}$ hydrogen bonds run along the crystallographic $a$-axis while the activated iodine of the TFDIB interacts with the carbonyl oxygen of the OA group and the pyridyl nitrogen (C) Top down view of the packing motif.

Refinement details for $p$-DPOA $\bullet(m \text {-TFDIB })_{2}$ : The compound crystallizes in the triclinic system. The space group P-1 (No. 2) was confirmed by structure solution. The asymmetric unit consists of half each of two independent $\mathrm{C}_{14} \mathrm{H}_{14} \mathrm{~N}_{4} \mathrm{O}_{2}$ molecules and two complete, independent $m$ - $\mathrm{C}_{6} \mathrm{~F}_{4} \mathrm{I}_{2}$ molecules. Both $\mathrm{C}_{14} \mathrm{H}_{14} \mathrm{~N}_{4} \mathrm{O}_{2}$ molecules lie on crystallographic inversion centers. All non-hydrogen atoms were refined with anisotropic displacement parameters. Hydrogen atoms bonded to carbon were located in Fourier difference maps before being placed in geometrically idealized positions and included as riding atoms with $\mathrm{d}(\mathrm{C}-\mathrm{H})=0.95 \AA$ and $\mathrm{Uiso}(\mathrm{H})=1.2 \mathrm{Ueq}(\mathrm{C})$ for aromatic hydrogen atoms and $\mathrm{d}(\mathrm{C}-\mathrm{H})=0.99 \AA$ and $\mathrm{Uiso}(\mathrm{H})=1.2 \mathrm{Ueq}(\mathrm{C})$ for methylene hydrogen atoms. The two independent hydrogen atoms bonded to nitrogen were located in difference Fourier maps and refined freely. The largest residual electron density peak in the final difference map is $0.78 \mathrm{e}-/ \AA 3$, located $1.44 \AA$ from H2BA. 
Table S18. Crystal data and structure refinement for $p$-DPOA $\bullet(m \text {-TFDIB })_{2}$

CCDC Identification code

Empirical formula

Formula weight

Temperature/K

Crystal system

Space group

$\mathrm{a} / \AA$

$\mathrm{b} / \AA$

$\mathrm{c} / \AA$

$\alpha /{ }^{\circ}$

$\beta /{ }^{\circ}$

$\gamma / 0$

Volume $/ \AA^{3}$

Z

$\rho_{\text {calc }} / \mathrm{cm}^{3}$

$\mu / \mathrm{mm}^{-1}$

$\mathrm{F}(000)$

Crystal size $/ \mathrm{mm}^{3}$

Radiation

$2 \Theta$ range for data collection/ ${ }^{\circ}$

Index ranges

Reflections collected

Independent reflections

Data/restraints/parameters

Goodness-of-fit on $\mathrm{F}^{2}$

Final $\mathrm{R}$ indexes $[\mathrm{I}>=2 \sigma(\mathrm{I})]$

Final R indexes [all data]

Largest diff. peak/hole / e $\AA^{-3}$
CCDC 1921268

$\mathrm{C}_{26} \mathrm{H}_{14} \mathrm{~F}_{8} \mathrm{I}_{4} \mathrm{~N}_{4} \mathrm{O}_{2}$

1074.01

100(2)

triclinic

P-1

$4.9570(3)$

15.3913(8)

20.6260(10)

$78.1590(10)$

83.402(2)

$85.474(2)$

1527.49(14)

2

2.335

4.161

996.0

$0.36 \times 0.02 \times 0.02$

$\operatorname{MoK} \alpha(\lambda=0.71073)$

4.408 to 56.68

$-6 \leq \mathrm{h} \leq 6,-19 \leq \mathrm{k} \leq 20,-27 \leq 1 \leq 27$

39474

$7618\left[\mathrm{R}_{\mathrm{int}}=0.0382, \mathrm{R}_{\text {sigma }}=0.0361\right]$

7618/0/406

1.076

$\mathrm{R}_{1}=0.0263, \mathrm{wR}_{2}=0.0474$

$\mathrm{R}_{1}=0.0416, \mathrm{wR}_{2}=0.0503$

$0.78 /-0.87$ 


\section{Structure, crystal data, and refinement for $p$-DPOA $\bullet$-TFDIB}

(A)

(B)
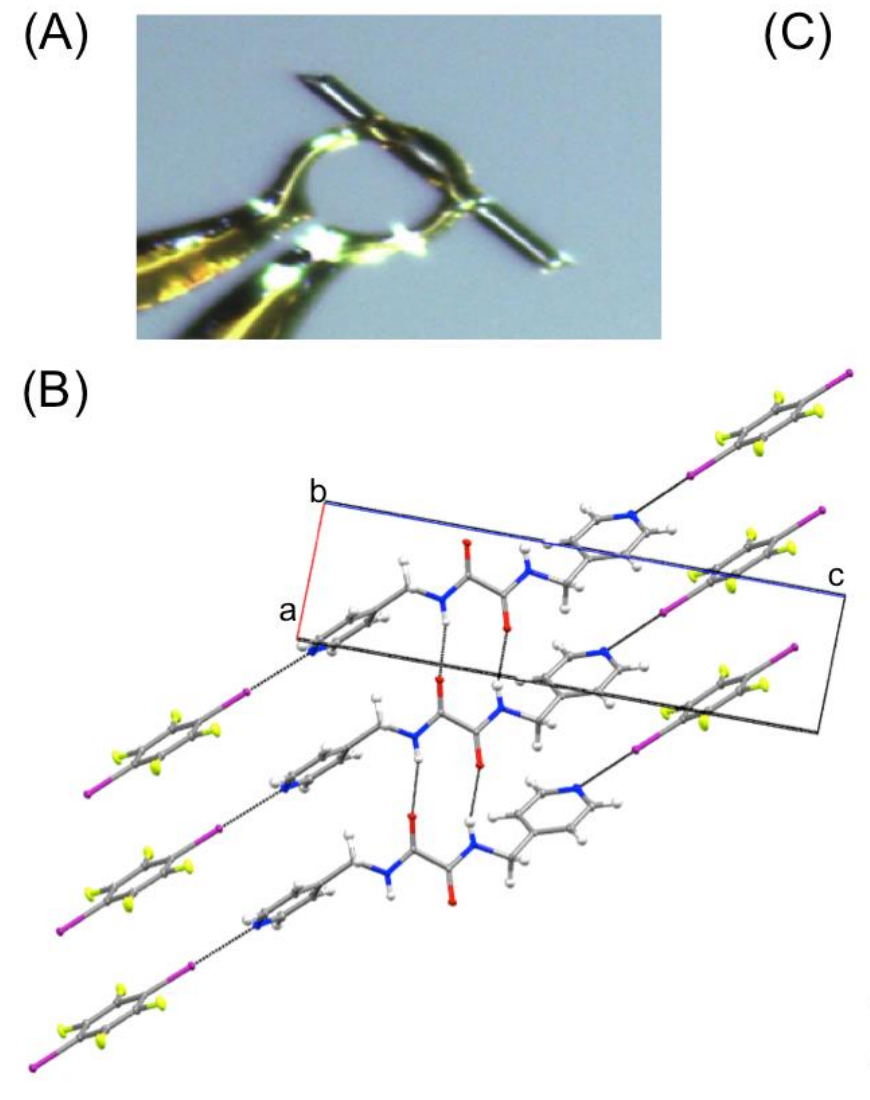

(C)

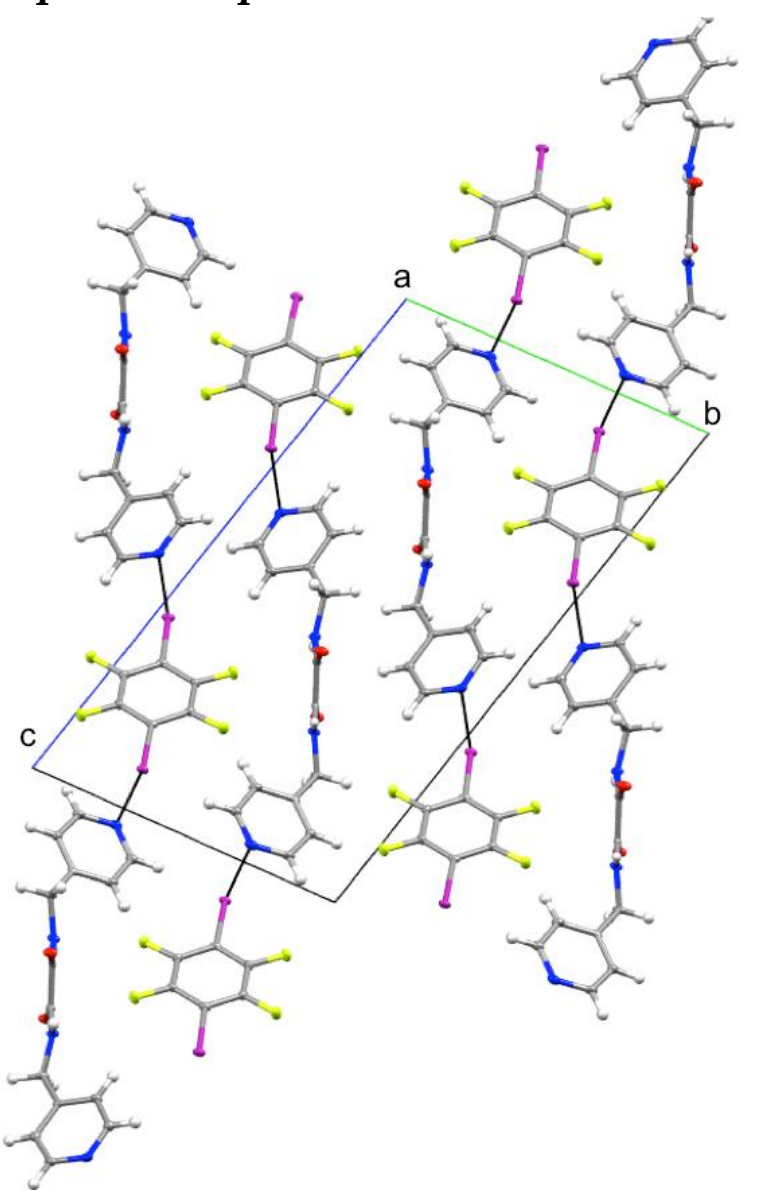

Figure S21. SC-XRD data of $p$-DPOA $p$-TFDIB. (A) Data crystal. (B) The DPOA molecules are organized through chains of $\mathrm{N}-\mathrm{H} \cdots \mathrm{O}$ hydrogen bonds along the crystallographic $a$-axis and infinite $\mathrm{N}-\mathrm{H} \cdots \mathrm{O}$ interactions along the $b c$ plane. (C) View down the $a$-axis showing the packing along the $b c$ plane.

Refinement details for $\boldsymbol{p}$-DPOA•p-TFDIB: The compound crystallizes in the triclinic system. The space group $P-1$ (No. 2) was confirmed by structure solution. The asymmetric unit consists of one $\mathrm{C}_{14} \mathrm{H}_{14} \mathrm{~N}_{4} \mathrm{O}_{2}$ molecule and one $\mathrm{C}_{6} \mathrm{~F}_{4} \mathrm{I}_{2}$ molecule. All non-hydrogen atoms were refined with anisotropic displacement parameters. Hydrogen atoms bonded to carbon were located in Fourier difference maps before being placed in geometrically idealized positions and included as riding atoms with $d(\mathrm{C}-\mathrm{H})=0.95 \AA$ and $U$ iso $(\mathrm{H})=1.2 U \mathrm{eq}(\mathrm{C})$ for aromatic hydrogen atoms and $d(\mathrm{C}-\mathrm{H})=0.99 \AA$ and $U$ iso $(\mathrm{H})=1.2 U$ eq $(\mathrm{C})$ for methylene hydrogens. The two unique hydrogen atoms bonded to nitrogen were located in Fourier difference maps and refined freely. The largest residual electron density peak in the final difference map is $0.57 \mathrm{e}^{-} / \AA^{3}$, located $0.60 \AA$ from N4. 
Table S19. Crystal data and structure refinement for $p$-DPOA $\bullet$-TFDIB.

\begin{tabular}{|c|c|}
\hline CCDC Identification code & CCDC 1921267 \\
\hline Empirical formula & $\mathrm{C}_{20} \mathrm{H}_{14} \mathrm{~F}_{4} \mathrm{I}_{2} \mathrm{~N}_{4} \mathrm{O}_{2}$ \\
\hline Formula weight & 672.15 \\
\hline Temperature/K & $100(2)$ \\
\hline Crystal system & triclinic \\
\hline Space group & $\mathrm{P}-1$ \\
\hline $\mathrm{a} / \AA$ & $5.0657(3)$ \\
\hline $\mathrm{b} / \AA$ & $10.9343(6)$ \\
\hline $\mathrm{c} / \AA \AA$ & $19.8004(10)$ \\
\hline$\alpha /^{\circ}$ & $104.5190(10)$ \\
\hline$\beta /{ }^{\circ}$ & $90.427(2)$ \\
\hline$\gamma /{ }^{\circ}$ & $92.915(2)$ \\
\hline Volume $/ \AA^{3}$ & $1060.11(10)$ \\
\hline Z & 2 \\
\hline$\rho_{\text {calc }} \mathrm{g} / \mathrm{cm}^{3}$ & 2.106 \\
\hline$\mu / \mathrm{mm}^{-1}$ & 3.028 \\
\hline$F(000)$ & 640.0 \\
\hline Crystal size $/ \mathrm{mm}^{3}$ & $0.38 \times 0.04 \times 0.03$ \\
\hline Radiation & $\operatorname{MoK} \alpha(\lambda=0.71073)$ \\
\hline $2 \Theta$ range for data collection $/{ }^{\circ}$ & 4.846 to 60.162 \\
\hline Index ranges & $-7 \leq \mathrm{h} \leq 7,-15 \leq \mathrm{k} \leq 15,-27 \leq 1 \leq 26$ \\
\hline Reflections collected & 42357 \\
\hline Independent reflections & $6202\left[\mathrm{R}_{\mathrm{int}}=0.0382, \mathrm{R}_{\text {sigma }}=0.0325\right]$ \\
\hline Data/restraints/parameters & $6202 / 0 / 298$ \\
\hline Goodness-of-fit on $\mathrm{F}^{2}$ & 1.007 \\
\hline Final $R$ indexes $[I>=2 \sigma(I)]$ & $\mathrm{R}_{1}=0.0242, \mathrm{wR}_{2}=0.0402$ \\
\hline Final $\mathrm{R}$ indexes [all data] & $\mathrm{R}_{1}=0.0399, \mathrm{wR}_{2}=0.0439$ \\
\hline Largest diff. peak/hole / e $\AA^{-3}$ & $0.57 /-0.58$ \\
\hline
\end{tabular}




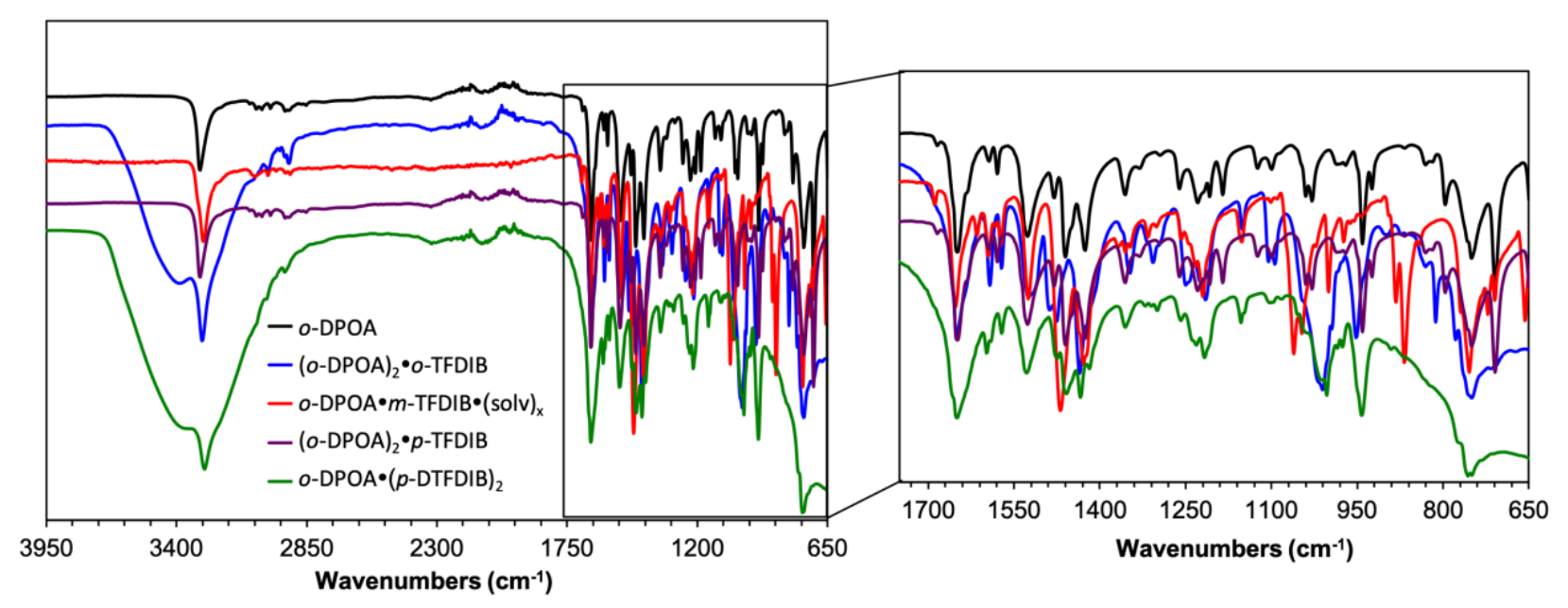

Figure S22. FT-IR of the $o$-DPOA co-crystal series.

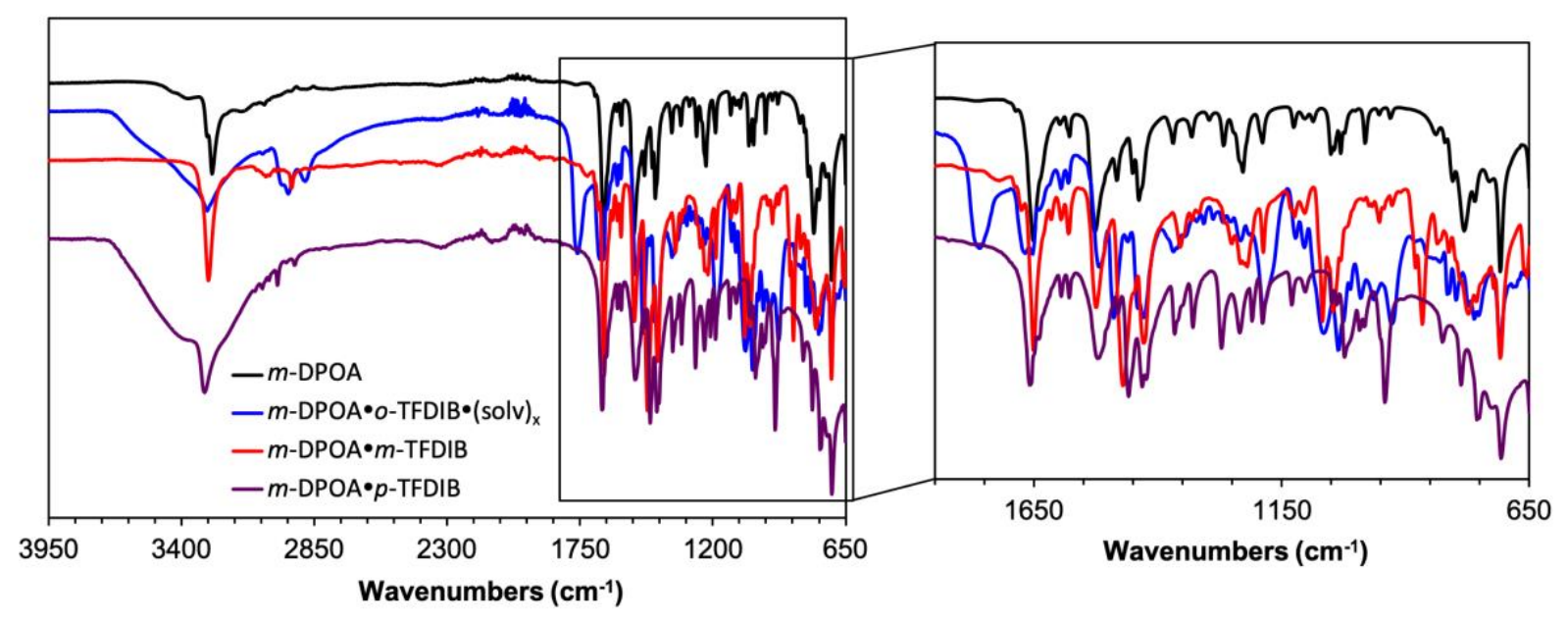

Figure S23. FT-IR of the $m$-DPOA co-crystal series. 


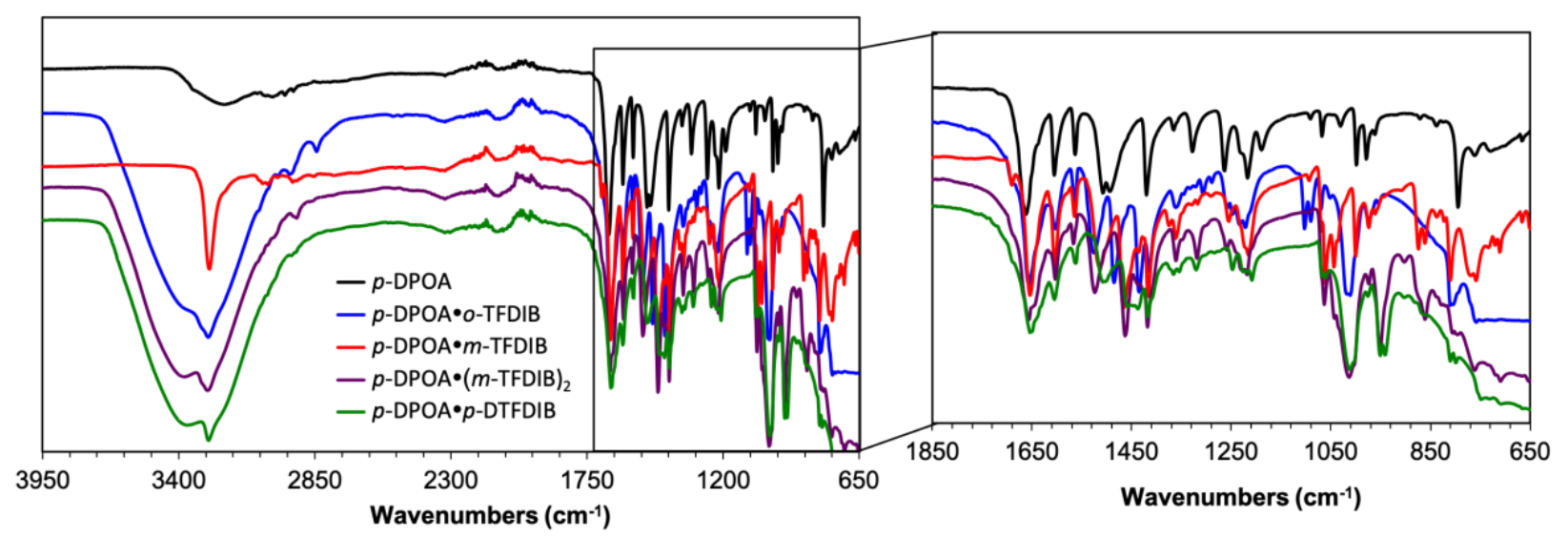

Figure S24. FT-IR of the $p$-DPOA co-crystal series.

\section{References}

(1) APEX3 Version 2016.5-0 and SAINT+ Version 8.37A. Bruker AXS, Inc., Madison, Wisconsin, USA, 2016.

(2) SADABS-2016/2: Krause, L., Herbst-Irmer, R., Sheldrick G.M. and Stalke D. J. Appl. Cryst. 2015, 48, 3-10.

(3) (a) SHELXT: Sheldrick, G.M. Acta Cryst. 2015, A71, 3-8. (b) SHELXL: Sheldrick, G.M. Acta Cryst. 2008, A64, 112-122.

(4) OLEX2: a complete structure solution, refinement and analysis program. Dolomanov, O. V., Bourhis, L. J., Gildea, R. J., Howard J. A. K. and Puschmann, H. J. Appl. Cryst. 2009, 42, 339341. 